\title{
Modeling the impact of river discharge and wind on the hypoxia off Yangtze Estuary
}

\author{
Jingjing Zheng ${ }^{1,2,3}$, Shan Gao ${ }^{1,3}$, Guimei Liu ${ }^{1,3}$, Hui Wang ${ }^{1,3}$, and Xueming Zhu ${ }^{1,3}$ \\ ${ }^{1}$ National Marine Environmental Forecasting Center, Beijing 100081, China \\ ${ }^{2}$ State Key Laboratory of Marine Environmental Science, Xiamen University, Xiamen 361005, China \\ ${ }^{3}$ Key Laboratory of Research on Marine Hazards Forecasting, National Marine Environmental Forecasting Center, \\ Beijing 100081, China
}

Correspondence to: Guimei Liu (liugm@nmefc.gov.cn)

Received: 9 April 2016 - Published in Nat. Hazards Earth Syst. Sci. Discuss.: 4 May 2016

Revised: 27 September 2016 - Accepted: 10 October 2016 - Published: 1 December 2016

\begin{abstract}
The phenomenon of low dissolved oxygen (known as hypoxia) in a coastal ocean system is closely related to a combination of anthropogenic and natural factors. Marine hypoxia occurs in the Yangtze Estuary, China, with high frequency and long persistence. It is related primarily to organic and nutrient enrichment influenced by river discharges and physical factors, such as water mixing. In this paper, a threedimensional hydrodynamic model was coupled to a biological model to simulate and analyze the ecological system of the East China Sea. By comparing with the observation data, the model results can reasonably capture the physical and biochemical dynamics of the Yangtze Estuary. In addition, the sensitive experiments were also used to examine the role of physical forcing (river discharge, wind speed, wind direction) in controlling hypoxia in waters adjacent to the Yangtze Estuary. The results showed that the wind field and river discharge have significant impact on the hypoxia off the Yangtze Estuary. The seasonal cycle of hypoxia was relatively insensitive to synoptic variability in the river discharge, but integrated hypoxic areas were sensitive to the whole magnitude of river discharge. Increasing the river discharge was shown to increase hypoxic areas, while decreasing the river discharge tended to decrease hypoxic areas. The variations of wind speed and direction had a great impact on the integrated hypoxic areas.
\end{abstract}

\section{Introduction}

In recent decades, the eutrophication of waterbodies driven by excess nutrient loads from lands due to human activities has increased year by year, which has led to an enhancement of hypoxic zone (Murphy et al., 2011; Rabouille et al., 2008). Dissolved oxygen (DO) threatens marine animals when its concentration is lower than $2 \mathrm{mg} \mathrm{L}^{-1}$ or $62.5 \mu \mathrm{mol} \mathrm{L}{ }^{-1}$, which is defined as hypoxia (Diaz, 2001; Wei et al., 2007). When DO is less than $2.0 \mathrm{mg} \mathrm{L}^{-1}$, the majority of marine aquatic organisms will die, especially benthic animals (Karlson et al., 2002). Hypoxia is one of the most severe environmental issues affecting estuarine and coastal marine ecosystems around the world. Hypoxia can reduce the diversity of marine species, change the community structure of marine organisms, reduce the richness of fish and benthic animals, and thus affect the fishery production and bring about direct or indirect economic loss (Yin et al., 2004).

The hypoxia off Yangtze Estuary was first found in 1959 $(\mathrm{Gu}, 1980)$. In recent years, with the increase of global warming and pollutant emissions, the hypoxic area off Yangtze Estuary expanded fast and became one of world's largest coastal hypoxia (Vaquer-Sunyer and Duarte, 2008). In the 1950 s, the occurrence probability of hypoxia off Yangtze Estuary in summer was $60 \%$, while after the 1990s hypoxia occurrence probability reached $90 \%$, and hypoxic areas which were greater than $5000 \mathrm{~km}^{2}$ basically occurred after the end of 1990s (Wang, 2009).

The formation of hypoxia adjacent to the Yangtze Estuary is a complex process, which is the result of both physical 
(b)

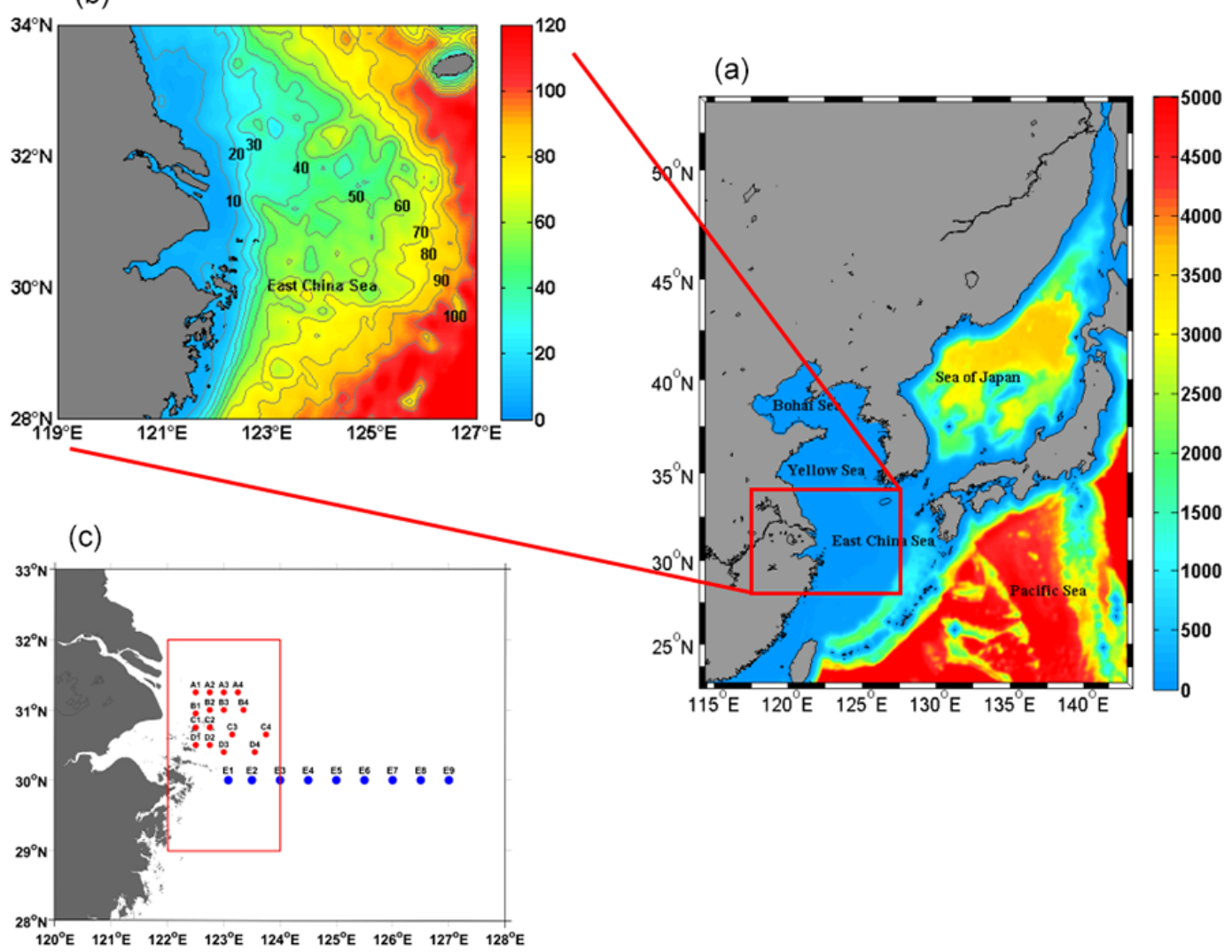

Figure 1. (a) Model domain and depth. Red box is the region of Fig. 1b. (b) The model bathymetry (shading map, unit: meter) of East China Sea. (c) Red dots are the station observation in August 2011; blue dots are the section observation in August 2011; the red rectangle indicates the region used for the calculation of $N^{2}$.

and biochemical processes. Previous research has shown that the formation and evolution of hypoxia was closely related to river discharge, Taiwan Warm Current, wind speed, wind direction, bottom topography, and the degradation of organic (Li et al., 2011; Ning et al., 2011; Wang, 2009; Zhou et al., 2010; Zhu et al., 2011). It was generally accepted that the increase in hypoxic extent was mainly driven by the rising anthropogenic nutrient input from the Yangtze River. However, many studies indicate that the physical factors have made important contributions to the formation of the annual variation of hypoxia. Wilson et al. (2008) found that the winddriven circulation had an important influence on the western Long Island Strait stratification and vertical mixing. When the wind direction changed in summer, it prevented the exchange of DO from the bottom to surface, which led to hypoxia on the western Long Island Strait. Through numerical simulation, Obenour (2015) found that the river nutrient concentration was very important for the formation of hypoxia. However, the stratification, which presented as a function of river discharge, wind speed, and wind direction, contributed to a larger extent to the interannual variability in hypoxia. Due to the limitation of observation data, it was difficult to fully understand the temporal and spatial variation of hypoxia and to quantitatively describe the influence of physical factors on the hypoxia off the Yangtze Estuary. In this paper, a three-dimensional hydrodynamic model (Regional Ocean Model System, ROMS) with a coupled nitrogen cycle model described by Fennel et al. (2006) was used to simulate ecosystem of the East China Sea. Through this coupled model, the effects of river discharge, wind speed, and wind direction on DO at sublayer and bottom of sea waters off the Yangtze Estuary were analyzed quantitatively.

\section{Model description}

\subsection{Physical model}

The physical circulation model used in this study was based on ROMS, which was a free-surface, terrain-following, primitive equation ocean model (Haidvogel et al., 2008; Shchepetkin et al., 2005). This model was built for the East China Sea $\left(114-143^{\circ} \mathrm{E}, 22.3-53.1^{\circ} \mathrm{N}\right)$ with a $1 / 15^{\circ}$ horizontal resolution and 30 vertical layers (Fig. 1a). The model's terrainfollowing vertical layers were stretched to result in increased 
resolution near the surface and bottom. A fourth-order horizontal advection scheme for tracers and a third-order mixing by Mellor and Yamad were used in the model (Mellor, 1982). At the offshore open boundary, we employed Chapman's condition for surface elevation (Chapman, 1985), Flather's condition for barotropic velocity (Flather, 1976), and a combination of radiation condition and nudging for tracers (Marchesiello et al., 2001).

The model was initialized with climatological temperature and salinity from the Generalized Digital Environment Model (GDEM) (Carnes, 2009). The south, north, and east of the pattern were open boundaries, and the west was a closed boundary. On the open boundary, the average profiles of temperature, salinity, and sea level were derived from Simple Ocean Data Assimilation (SODA, http://dsrs.atmos. umd.edu/DATA/soda_2.2.4/). The model was forced with net heat flux, fresh water flux, shortwave radiation, wind stress, and so on, which derived from NCEP/CFSR reanalysis (http: //rda.ucar.edu/datasets/ds093.0). In the model, the runoff of the Yangtze River was determined by the monthly average discharge of the Datong station (Liu et al., 2002).

\subsection{Biological model}

The biological module was based on the nitrogen cycle model described in the study by Fennel et al. (2006). The model included 10 state variables: two species of dissolved inorganic nitrogen (nitrate, $\mathrm{NO}_{3}$, and ammonium, $\mathrm{NH}_{4}$ ), one phytoplankton group, one zooplankton group, chlorophyll, two-species detritus representing large, fast-sinking particles and suspended, small particles, and oxygen, total inorganic carbon, and alkalinity. The sources of DO in the model were air-sea gas exchange and primary production, and the sink included the respiration zooplankton, nitrification, decomposing detritus, and sediment oxygen consumption (Fennel et al., 2013). At the sediment-water interface, the model assumed "instantaneous remineralization" by which organic matter that sank to the bottom was remineralized immediately to ammonium and oxygen was taken up immediately as well. The initial fields and boundary conditions for the biological tracers were derived from the World Ocean Atlas 2009 (WOA2009, http://www.nodc.noaa.gov/OC5/WOA09/ pr_woa09.html). The initial value of ammonium was set to $1 \mathrm{mmol} \mathrm{m}^{-3}$. The chlorophyll concentration was extrapolated in the vertical direction from surface values specified by SeaWiFS monthly climatological data and the extrapolation was based on the generalized Gaussian curve of typical pigment profile (Lewis et al., 1983; Morel and Berthon, 1989). The initial values of phytoplankton, zooplankton, and detritus concentrations were set to $0.5,0.25$, and 0.25 times the chlorophyll concentration, respectively (Liu et al., 2002). Ammonium can be rapidly nitrified into nitrate at the inner estuaries. Therefore, only nitrate discharged from the Yangtze River was considered in the model.
After the physical model had spun up for 10 years from climatological 1 January, the coupled physical-biological model was simulated from 1 January 2006 to 31 December 2011. A series of numerical experiments in 2010 were set up to study the influence of river discharge, wind speed, and wind direction on hypoxia adjacent to the Yangtze Estuary.

\section{Results}

\subsection{Model validation}

The model results and some observational data in the East China Sea were available to validate the model. These include monthly climatological values for sea surface temperature (SST) and sea surface salinity (SSS) with $1 / 4^{\circ}$ spatial resolution from GDEM, sea surface chlorophyll and SST with a spatial resolution of $4 \mathrm{~km}$ from MODIS in $\mathrm{Au}-$ gust 2011, and in situ biochemical data obtained from a summer cruise in August 2011. Figure 1c showed the cruise observations along the section $\mathrm{E}$ with blue dots and sampling stations with red dots.

The comparison of SST and SSS in August between the model and GDEM is shown in Fig. 2. The model fields of SST and SSS were the monthly mean climatological simulation for 10 years, and the GDEM fields are the monthly mean climatology data. The SST and SSS comparison shows the model performance is similar to the GDEM. The root mean square errors (RMSEs) of SST and SSS are approximately 1.18 and 0.86 for both model and GDEM. The spatial distribution characteristic of SST gradually increased from north to south. The model results of the SST along the coastal waters were higher than GDEM data, especially on the shores of Bohai and the Yellow Sea. From the difference of SSS between simulated results and GDEM data, we found a certain deviation between them near the Yangtze Estuary. In reality, the GDEM data were not very accurate along the Chinese coast due to its low spatial resolution. The distributions of SSS in our model were comparable to the results conducted by Liu et al. (2010).

Figure 3 shows the distribution of modeled SST in August 2011 compared with remote sensing data from MODIS. The SST comparison showed that the model performance was similar with the MODIS. SST in the southern East China Sea was higher than in the north. From the SST distribution, we found a strong cold water tongue appearing off Hangzhou Bay. Another low SST center was situated at $122-124^{\circ} \mathrm{E}$, $33^{\circ} \mathrm{N}$, near Jiangsu coast, which was consistent with the results reported by Lü et al. (2006). The low-temperature region in surface layer water was usually an effective index for identifying the upwelling.

Figure 4 shows the surface current distribution in January and August 2011. In January, under the control of northerly wind, the southward currents were found on the 
(a)

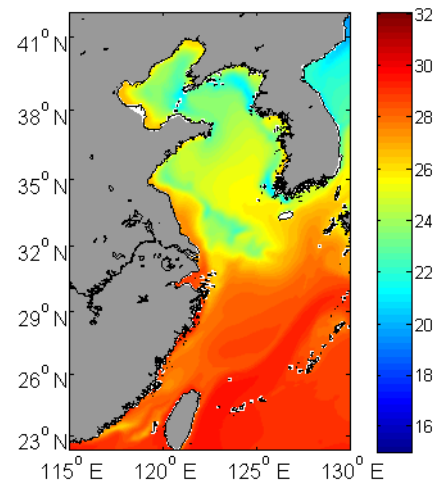

(d)

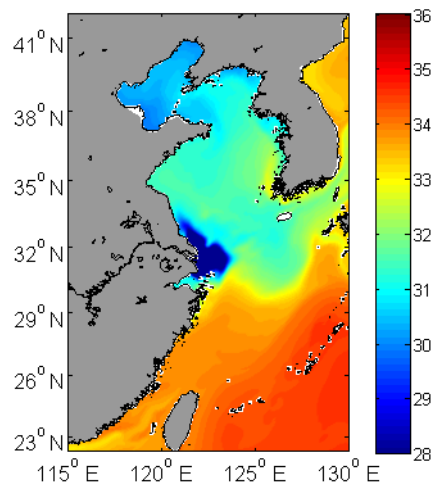

(b)

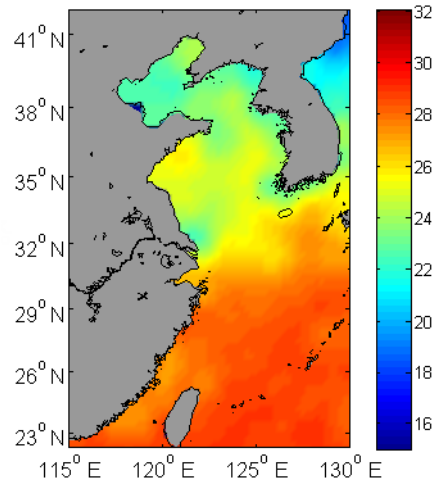

(e)

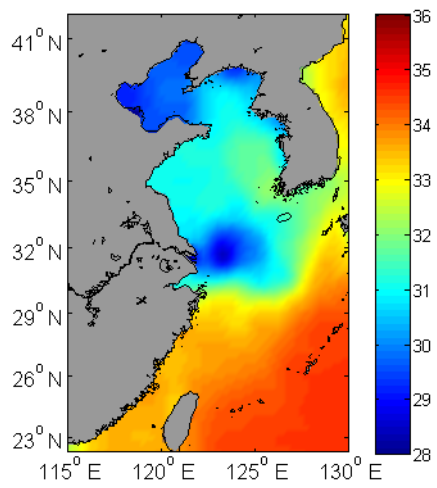

(c)

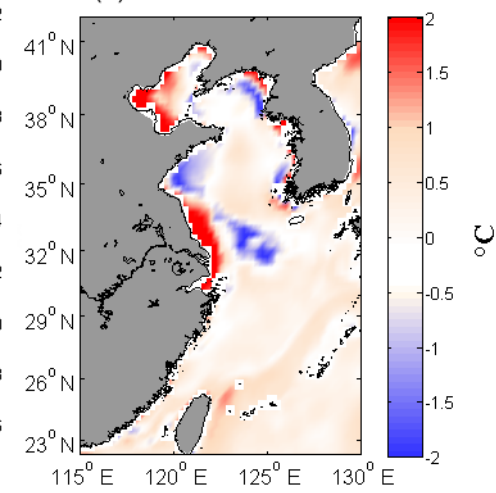

(f)

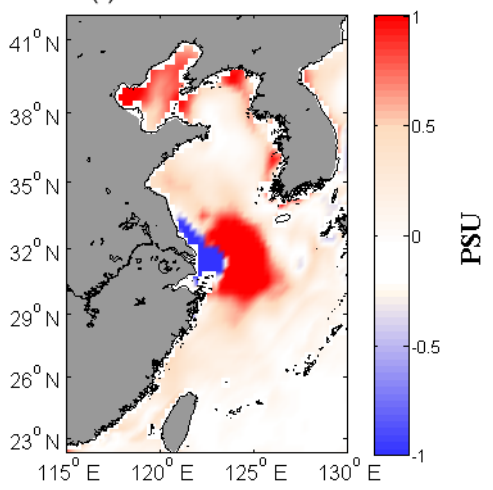

Figure 2. The comparison between modeled results (a) and GDEM data (b) of climatological field of SST in August, and the difference between them (c). The comparison between modeled results (d) and GDEM data (e) of climatological field of SSS in August, and the difference between them (f).

(a) Model-SST

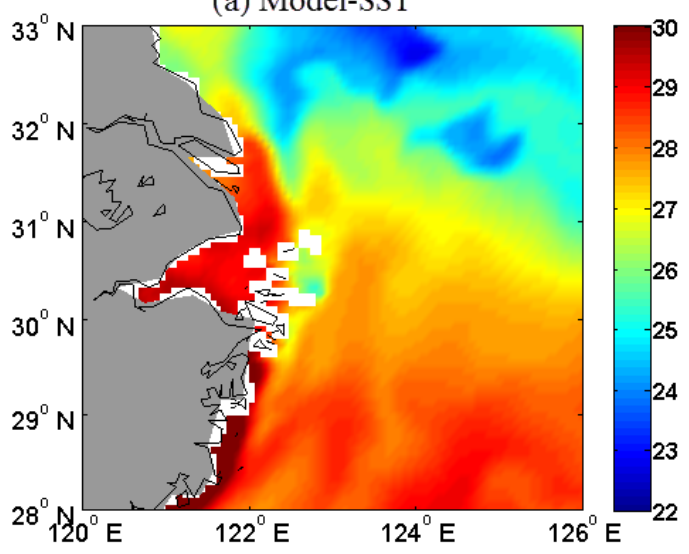

(b) MODIS-SST

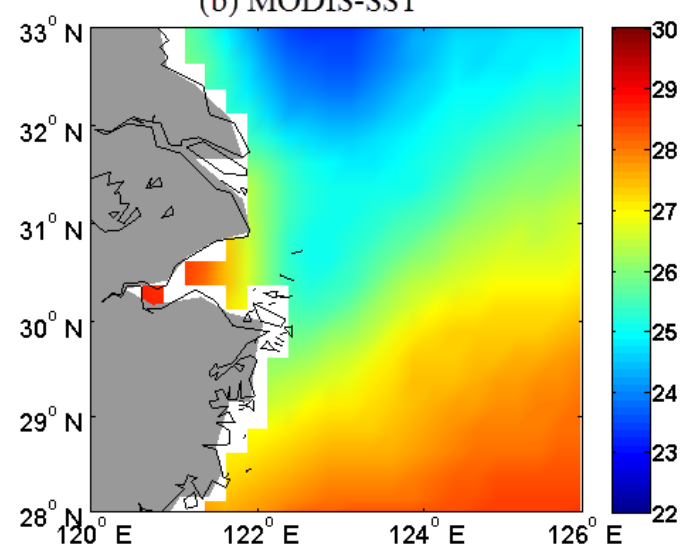

Figure 3. SST distributions in August 2011: (a) model result of SST; (b) remotely sensed SST $\left({ }^{\circ}\right.$ C; MODIS).

shelf of East China Sea. Taiwan Warm Current was weakened and extended northward. The Yangtze diluted water flowed southwestward along the Zhejiang coast and became a major part of Zhejiang coastal current. In August, the Taiwan Warm Current originated from Taiwan Strait and flowed strongly into the East China Sea. Initially, Taiwan Warm Current flowed northeastward as a whole and then divided into two branches near $28^{\circ} \mathrm{N}$. The offshore branch flowed northeastward and finally into Tsushima Strait, while the inshore branch extended northward to the Yangtze Estuary along the Zhejiang coast. Yangtze diluted water extended to the northeast under the control of southerly wind.

Figure $5 \mathrm{a}$ and $\mathrm{b}$ show the comparison of sea surface chlorophyll concentration between the model results and 
(a) Jan

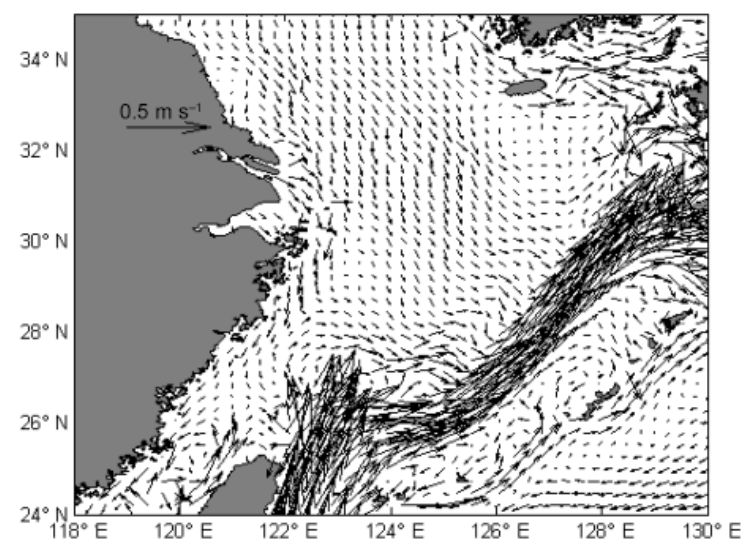

(a) Aug

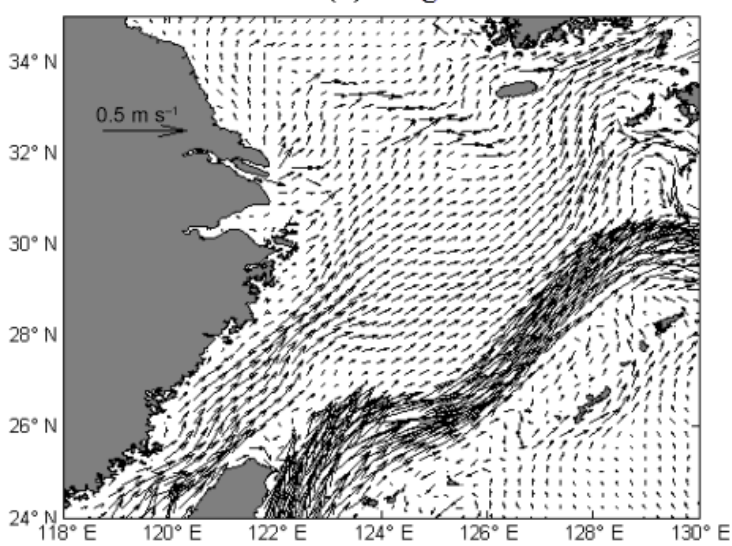

Figure 4. The numerically simulated circulation pattern: (a) January 2011; (b) August 2011.

MODIS-derived data in August 2011. With regard to chlorophyll, the RMSE is 1.31. It can be seen that the patterns of chlorophyll were comparable to the MODIS-derived data. For example, the distribution of chlorophyll extended northeast in summer. The chlorophyll $a$ concentration was 5$10 \mathrm{mg} \mathrm{m}^{-3}$ in surface waters adjacent to the Yangtze Estuary, then decreased rapidly eastward to the open shelf, where values were $0.1-0.5 \mathrm{mg} \mathrm{m}^{-3}$. The modeled chlorophyll values in the inner and mid-shelves were quite close to the MODISderived data, while the model generally underestimated the chlorophyll in the outer shelf. Compared with the MODISderived data, the concentration of chlorophyll south of $28^{\circ} \mathrm{N}$ was also lower. This was mainly due to only considering the nutrient inputs from the Yangtze River in the model.

In situ nitrate and ammonium distributions along section $30^{\circ} \mathrm{N}$ (see Fig. 5) in August 2011 were used to evaluate the simulation capability of the biological model. Both in situ and model nitrate distributions showed that the presence of nitrate was relatively high at the bottom $\left(>4 \mathrm{mmol} \mathrm{m}^{-3}\right)$ but low $\left(<2 \mathrm{mmol} \mathrm{m}^{-3}\right)$ at the surface. An analogous structure was present in the in situ temperature and salinity distributions located between 123 and $124^{\circ} \mathrm{E}$ reported by Wang (2009), so that upwelled water inside the trough involved not only low temperature and high salinity but also high levels of nutrients. In Fig. 5c and d, a definite deviation between the model and in situ data can be seen. The high nitrate concentration appeared above water layers of $25 \mathrm{~m}$ along the section at $123^{\circ} \mathrm{E}$, but the model failed to reproduce it. The underestimation probably resulted from the insufficient dispersion of high nitrate, which was a source from Yangtze River diluted water. Along the section at $30^{\circ} \mathrm{N}$, the patterns of model ammonium resembled those of observations. Ammonium was relatively high in the near-shore waters $\left(>2 \mathrm{mmol} \mathrm{m}^{-3}\right)$, then decreased toward the open waters $\left(<1 \mathrm{mmol} \mathrm{m}^{-3}\right)$. An obvious high-concentration area was located between 123 and $123.5^{\circ} \mathrm{E}$, which reconfirmed that the upwelling brought the bottom water with high nutrients to the surface.

Figure 6 shows the comparison between in situ and model results of $\mathrm{DO}$ and nitrate concentration at the stations in $\mathrm{Au}-$ gust 2011 (see Fig. 1c). It can be seen that the simulated DO and nitrate resembled the in situ data. The RMSEs of surface DO, bottom DO, surface nitrate, and bottom nitrate were $0.55,0.56,1.58$, and 1.94 , respectively. The mean bias $\mathrm{Mb})$ was defined as the difference between average values of models and observations. The $\mathrm{Mb}$ of surface $\mathrm{DO}$ and bottom DO was $-0.31 \mathrm{mmol} \mathrm{m}^{-3}$ and $0.1 \mathrm{mmol} \mathrm{m}^{-3}$, respectively, which is acceptable. With regard to the bottom nitrate, $\mathrm{Mb}=0.79 \mathrm{mmol} \mathrm{m}^{-3}$ indicated that the model overestimates the bottom nitrate on average, while the surface nitrate performed much better with $\mathrm{Mb}=-0.1 \mathrm{mmol} \mathrm{m}^{-3}$. The concentration of DO in the surface layer was generally high $\left(>6 \mathrm{mg} \mathrm{L}^{-1}\right)$, while it was low in the bottom water.

The distribution of DO adjacent to the Yangtze Estuary in September 2010 is shown in Fig. 7. On the whole, it indicates that the distribution of DO was high in the north and low in the south. A closed area with oxygen level less than $2.0 \mathrm{mg} \mathrm{L}^{-1}$ appeared off Yangtze Estuary and extended along the Yangtze Estuary to the Zhejiang coastal water.

\subsection{The impacts of river discharge on hypoxia}

To evaluate the role of the seasonal variation in river discharge on the hypoxic area, we conducted a sensitivity experiment (denoted as $Q_{\text {const }}$ ) where river discharge was set to the annual mean value for 2010 and the other conditions were the same as the base model run (Tables 1,3). The extent of hypoxic water off the Yangtze Estuary can be quantified by calculating the total area of water that has bottom DO concentrations below different threshold values $(1.0,2.0$, $\left.3.0 \mathrm{mg} \mathrm{L}^{-1}\right)$. If there was no special note, the hypoxic area was denoted as the area of $\mathrm{DO}<2 \mathrm{mg} \mathrm{L}^{-1}$ in this paper. In the base model run, the hypoxic zone first appeared off the 
(a)

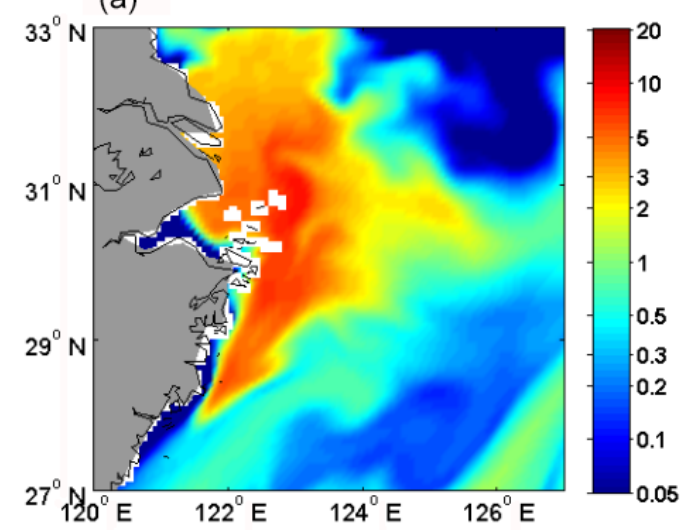

(c)

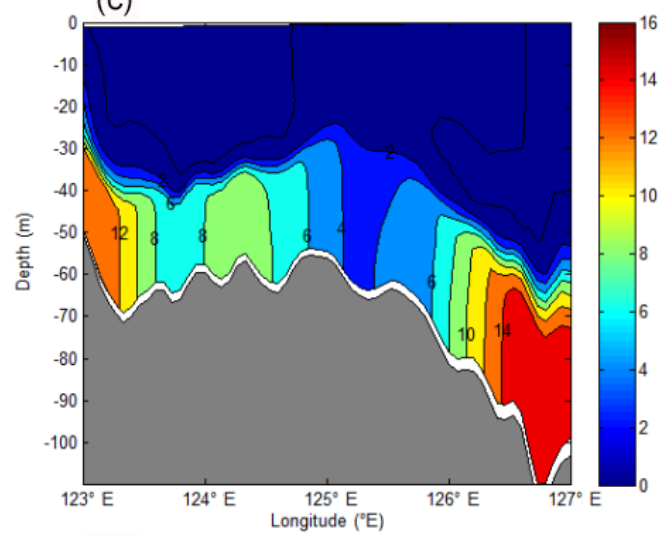

(e)

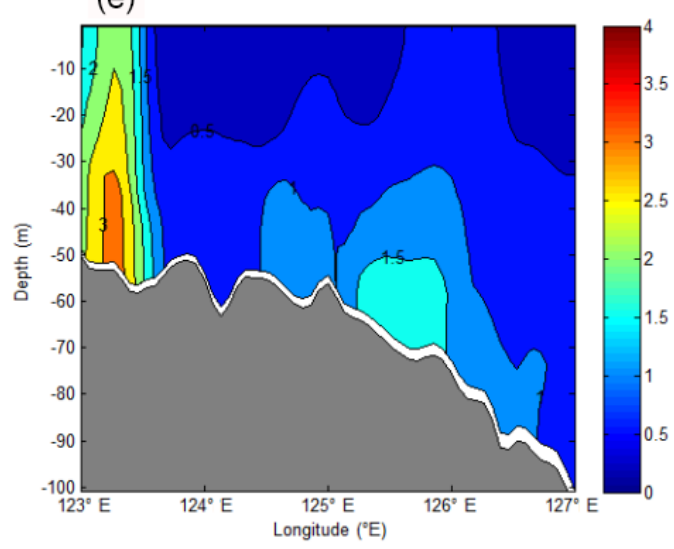

(b)

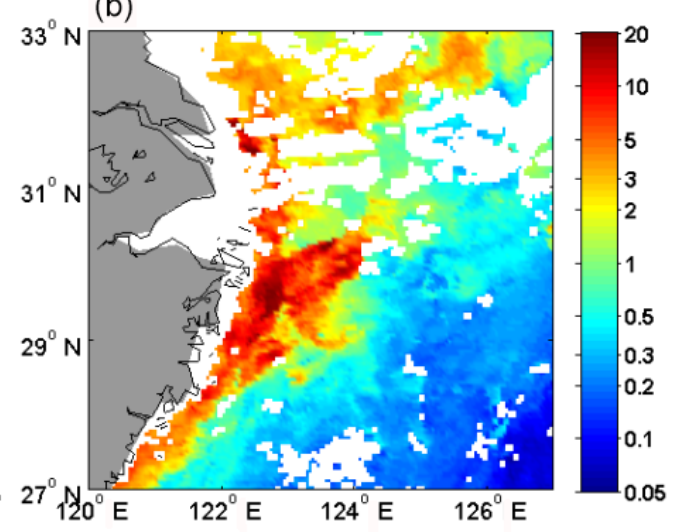

(d)

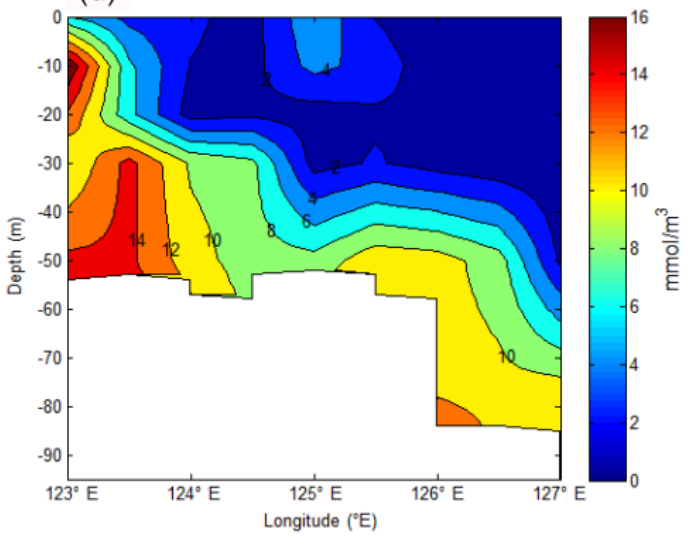

(f)

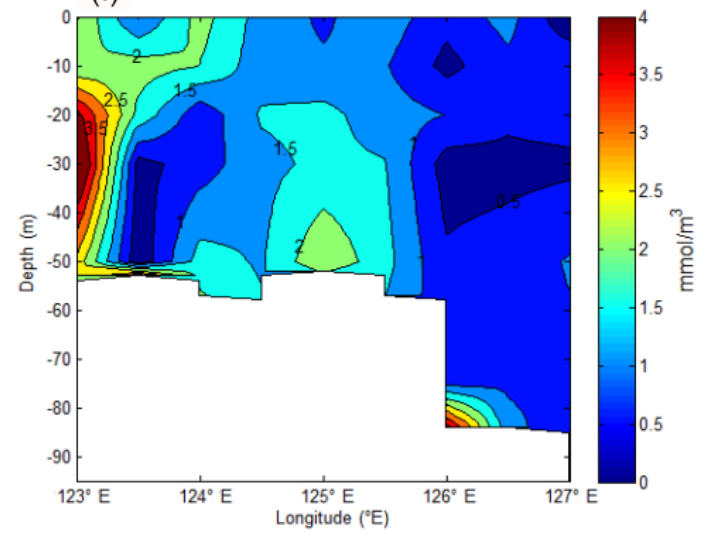

Figure 5. The comparison between modeled results (a) and MODIS-derived data (b) of chlorophyll $a$ concentration in August 2011. The comparison between modeled results (c) and in situ data (d) of $\mathrm{NO}_{3}$ along the section at $30^{\circ} \mathrm{N}$ in August 2011. The comparison between modeled results (e) and in situ data (f) of $\mathrm{NH}_{4}$ along the section at $30^{\circ} \mathrm{N}$ in August 2011.

Yangtze Estuary in August, then reached its peak in September before finally reducing and gradually disappearing in October (Fig. 8a). The results were consistent with the findings of previous work conducted by Wei (2015). As shown in Fig. 8a, the seasonal variations in the hypoxic area in the $Q_{\text {const }}$ run were almost consistent with the base model run, which suggested that the seasonal variation of the hypoxic area was not remarkably affected by the temporal variation of the river discharge of Yangtze River. In addition, the area of the bottom DO concentration of less than 1,2 , and $3 \mathrm{mg} \mathrm{L}^{-1}$ decreased by 32,46 , and $19 \%$ (Table 2), respectively, in the $Q_{\text {const }}$ run. Next, to evaluate the role of magnitude of river discharge, we conducted $Q_{2}$ and $Q_{0.5}$ sensitivity experiments where the temporal variation in river discharge was preserved but the magnitude was doubled or halved for 2010 . Doubling the river discharge increased the area where the 
(a)

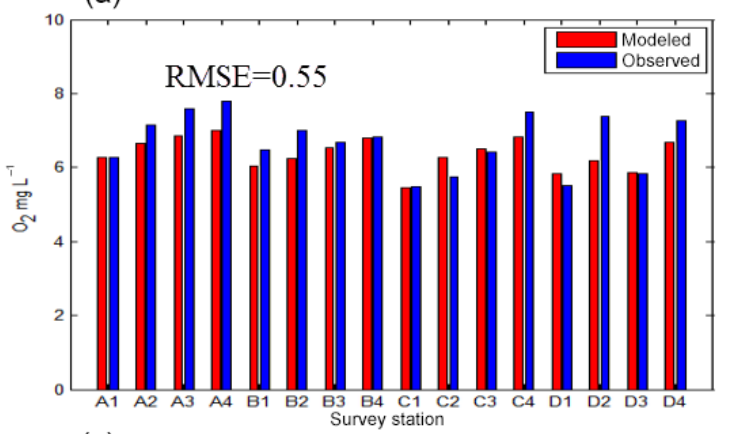

(c)

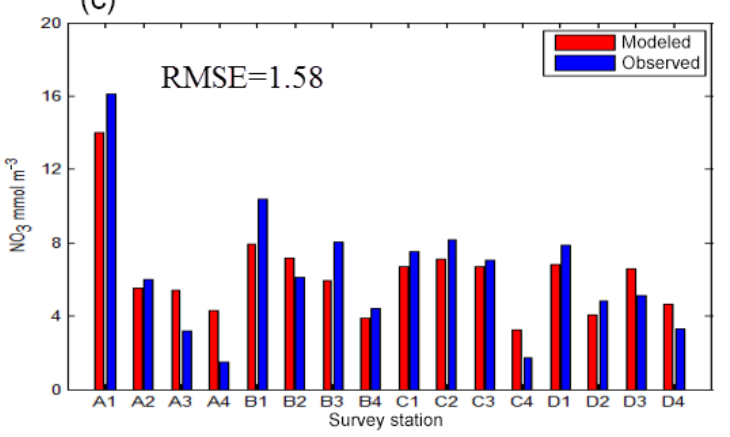

(b)

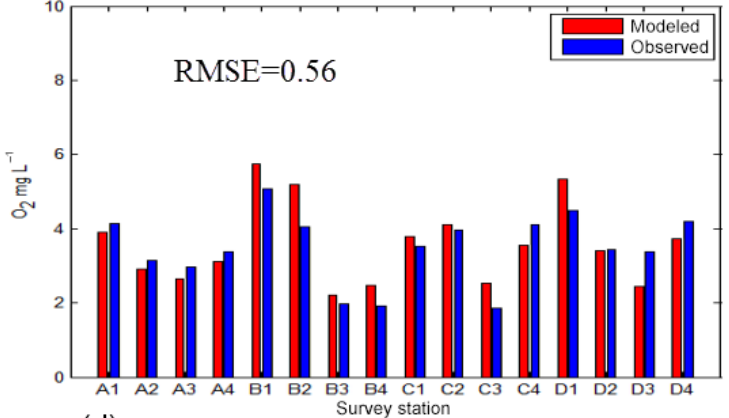

(d)

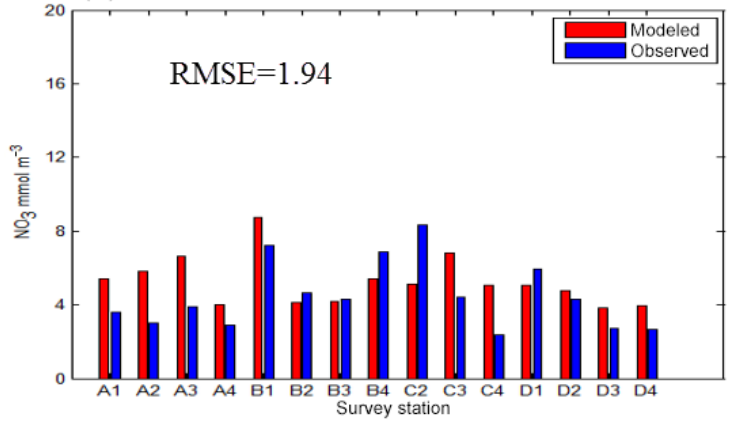

Figure 6. The comparison between modeled results (red bars) and observed data (blue bars) of $\mathrm{NO}_{3}$ and $\mathrm{DO}$ at the stations in August 2011 (see Fig. 1c). (a) Surface DO; (b) bottom DO; (c) surface $\mathrm{NO}_{3}$ concentration; (d) bottom $\mathrm{NO}_{3}$ concentration.

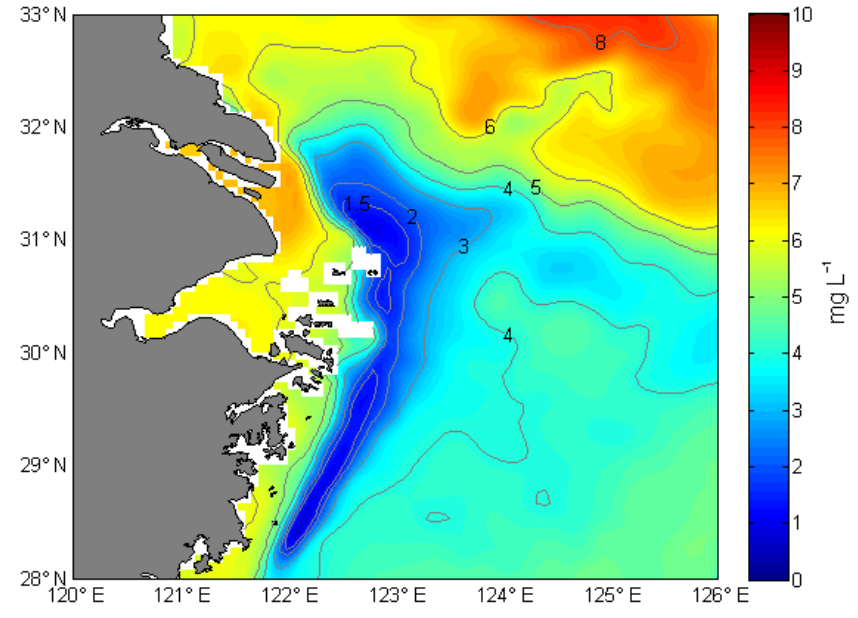

Figure 7. The modeled patterns of hypoxic zone off the Yangtze Estuary in September 2010.

bottom DO concentration was below the minimum threshold by nearly 7 times $\left(1 \mathrm{mg} \mathrm{L}^{-1}\right)$. A reduction in the river discharge by $50 \%$ decreased the total integrated hypoxic area by $20 \%$ to nearly $63 \%$ under different threshold values.

Water stratification prevented the vertical exchange of DO, and it was an essential condition for the formation of hypoxia. In this paper, frequency Brunt-Väisälä $\left(N^{2}\right)$ was calculated to quantify the stratification strength, and it was de- noted as the stratification strength between the surface and bottom water (Goni et al., 2006). The greater the $N^{2}$ was, the stronger the stratification of the water. The calculating area of $N^{2}$ is shown in Fig. 1c of the red rectangle. $N^{2}$ was calculated for 2010 in all model runs.

$N^{2}=-\frac{g}{\rho} \frac{\partial \rho}{\partial z}$

As shown in Fig. 8b, the stratification of water adjacent to the Yangtze Estuary had a significant relationship with the river discharge. Doubling the river discharge increased markedly the stratification strength, while reducing the discharge to $50 \%$ of the base model run led to a significant decrease in the stratification. Figure 9 shows the correlation of concentration between the bottom DO and the $N^{2}$. We could found that $N^{2}$ was inversely proportional to the concentration of bottom DO. The stronger the stratification was, the lower the concentration of bottom DO. The absolute values of correlation coefficient were higher than 0.6 . The maximum of absolute correlation coefficient was 0.73 in the $Q_{2}$ run, while the minimum in the $Q_{\text {const }}$ run was 0.6 . The absolute correlation coefficient was 0.67 and 0.64 , respectively, in the base and $Q_{0.5}$ run. From Fig. 9 we see that the bottom DO had a 3month lag with stratification. This was presumably because the decrease of bottom DO was the combined result of stratification and oxygen consumption. The latter was associated with the decay of dead phytoplankton. The strongest stratification occurred in July when sediment oxygen consumption 
Table 1. Model sensitivity experiment.

\begin{tabular}{ll}
\hline Experiments & Description \\
\hline Base model run & \\
\hline Base & Base run with realistic river discharge and wind forcing in year 2010 \\
\hline River discharge runs & \\
\hline$Q_{\text {const }}$ & River discharge was set to annual average value \\
$Q_{2}$ & Double the river discharge \\
$Q_{0.5}$ & Halve the river discharge \\
\hline Wind runs & \\
\hline$W_{\mathrm{Jan}}$ & Winds from January were repeated for every month of the year \\
$W_{\text {Aug }}$ & Winds from August were repeated for every month of the year \\
$W_{0.9}$ & Summer (July-September) wind magnitude decreased by $10 \%$ \\
$W_{1.1}$ & Summer (July-September) wind magnitude increased by $10 \%$ \\
$W_{180^{\circ}}$ & Summer (July-September) wind direction rotated $180^{\circ}$ \\
$W_{-90^{\circ}}$ & Summer (July-September) wind direction rotated negative $90^{\circ}$ \\
$W_{+} 90^{\circ}$ & Summer (July-September) wind direction rotated positive $90^{\circ}$ \\
\hline
\end{tabular}

was relatively low. As a result, the bottom DO concentration was not the lowest in July, and the DO had a 3-month lag with stratification.

\subsection{The impacts of wind forcing on hypoxia}

The wind forcing also had a significant effect on the occurrence and development of hypoxia. Increasing wind speed enhanced the vertical mixing of water and promoted the vertical exchange of DO, which led to a break in the formation of hypoxia (Scully, 2010b). The Yangtze Estuary is mainly controlled by the East Asian monsoon. The wind speed and wind direction have obvious seasonal variability over the Yangtze Estuary, namely low magnitude and dominantly southerly direction in summer (July to September) and relatively high magnitude and northerly direction in winter. In order to evaluate the role of seasonal changes in wind forcing, we conducted wind runs where the August wind (denoted as $W_{\text {Aug }}$ ) and January wind (denoted as $W_{\mathrm{Jan}}$ ) were repeated each month of 2010. By forcing the model in this way, the winds had daily variations associated with the passage of weather systems, but the seasonal variations of speed and direction were removed. Although this kind of situation did not exist in practice, it was helpful for us to further understand the impacts of wind forcing on hypoxia. The seasonal variability of wind speed and direction had a great impact on the integrated hypoxic area. When strong, northerly winds in January were repeated all year in the $W_{\text {Jan }}$ run, and the hypoxia off the Yangtze Estuary nearly disappeared. This implied that the hypoxic area of seasonal variation did not exist under the strong wind. In contrast, in the $W_{\text {Aug }}$ run, the light, southerly winds were repeated all year and the hypoxia was extensive from July to October (Fig. 10a). This suggested that the low constant wind also could lead to the seasonal cycle of hy- poxia. The integrated hypoxic area $\left(\mathrm{DO}<2 \mathrm{mg} \mathrm{L}^{-1}\right)$ in $W_{\text {Aug }}$ increased roughly $25 \%$ compared to the base model run (Table 2). The hypoxic area was the largest in summer, while essentially no hypoxia was simulated in the other months. A possible reason was that the phytoplankton was affected by water temperature and decreased in early spring and winter, so that the consumption of DO was reduced due to organic matter decomposition.

To further examine the effects of wind speed on the hypoxia, we conducted a $W_{0.9}$ wind run in which the wind speed decreased $10 \%$ and a $W_{1.1}$ wind run in which the wind speed increased by $10 \%$ during the summer (July to September). The magnitude of summer wind speed had a significant impact on the hypoxic area off the Yangtze Estuary. When summer wind speed decreased, the integrated hypoxic area increased by roughly $45 \%$. When wind speed increased in summer, it led to a reduction by nearly $64 \%$ of hypoxic area (Table 2).

Previous studies suggested that the hypoxic area was also sensitive to wind direction (Scully, 2010a; Xia and Jiang, 2015). To further evaluate the influence of wind direction on the hypoxia, we conducted the model runs in which summer wind direction (July to September) was systematically varied in the model forcing. As is typical in most summers, the wind during the 2010 summer is predominately from the south. In the wind direction sensitivity runs, the modeled wind forcing during the summer (July to September) was rotated by $180^{\circ}$ $\left(W_{180^{\circ}}\right)$, negative $90^{\circ}\left(W_{-90^{\circ}}\right)$, and positive $90^{\circ}\left(W_{+90^{\circ}}\right)$, resulting in model forcing of the summer winds from the north, east, and west, respectively (Table 1). Although these simulations were not realistic, they provide insights into the impacts of wind direction on the hypoxia. When the summer wind direction was from the north $\left(W_{180^{\circ}}\right)$, the integrated hypoxic 
(a)

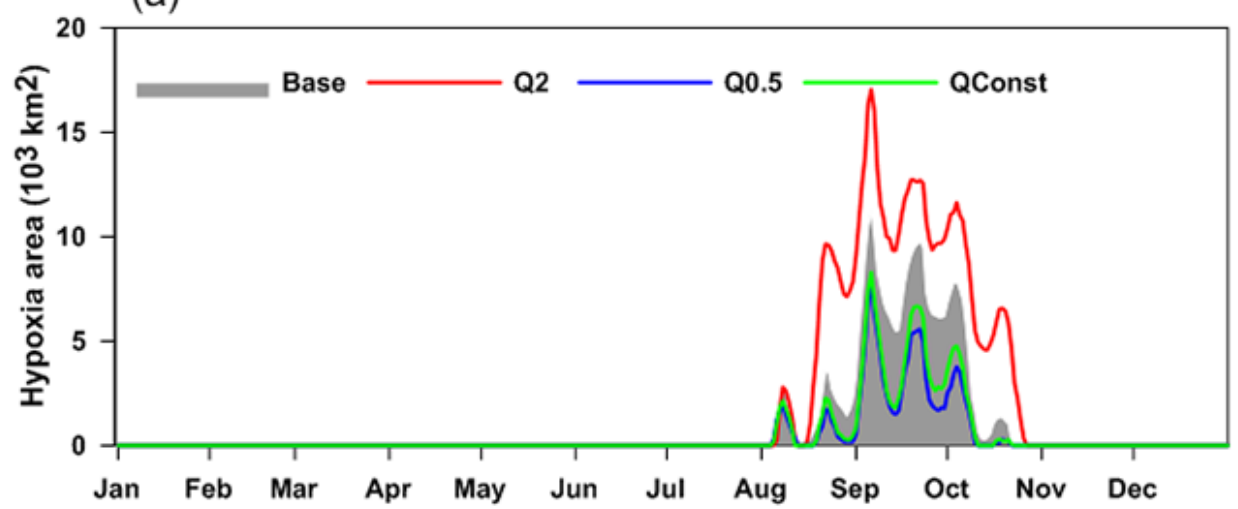

(b)

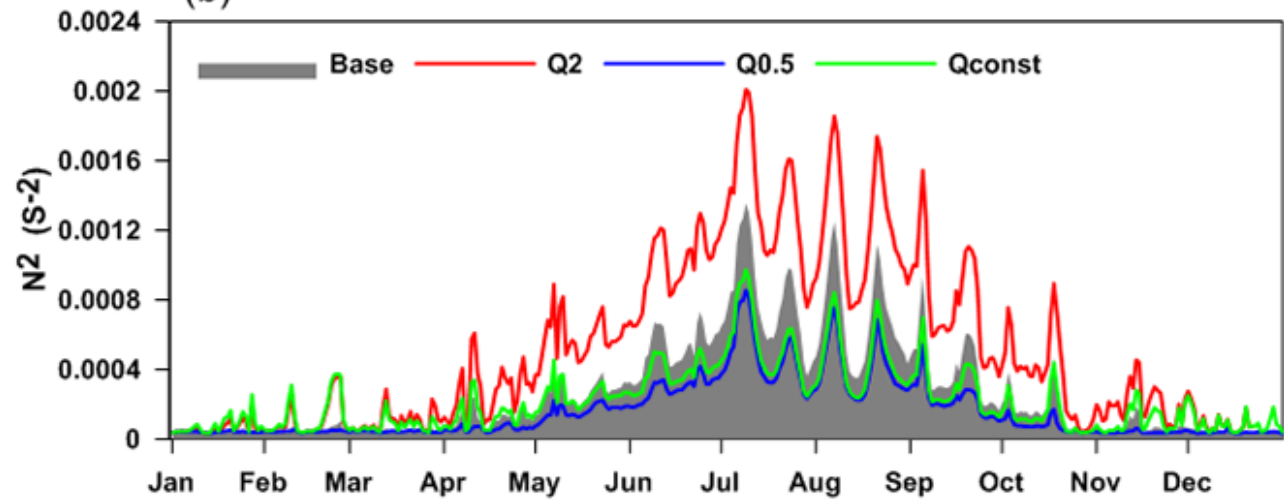

Figure 8. (a) and (b) are the hypoxic area $\left(\mathrm{DO}<2 \mathrm{mg} \mathrm{L}^{-1}\right)$ and $N^{2}$ in the river discharge experiment, respectively. The gray shaded part represents the base run and the red, blue, and green curves represent $Q_{2}, Q_{0.5}$, and $Q_{\text {const }}$, respectively.

Table 2. The total area of hypoxic area under different thresholds of DO, the average $N^{2}$ in summer, and the year.

\begin{tabular}{lrrrrr}
\hline Experiments & \multicolumn{3}{c}{$\begin{array}{c}\text { Integrated hypoxic area } \\
\left(10^{3} \mathrm{~km}^{2} \text { days }\right)\end{array}$} \\
\hline \multicolumn{1}{c}{$<\mathrm{mg} \mathrm{L}^{-1}$} & $<2 \mathrm{mg} \mathrm{L}^{-1}$ & $<3 \mathrm{mg} \mathrm{L}^{-1}$ & Summer average & Yearly average \\
\hline Base model run & & & & \\
Base & 11.7 & 330.5 & 1163 & $5.58 \times 10^{-4}$ & $2.63 \times 10^{-4}$ \\
\hline River runs & & & & \\
$Q_{\text {const }}$ & $8.0(-32 \%)$ & $179.6(-46 \%)$ & $939.3(-19 \%)$ & $3.80 \times 10^{-4}(-32 \%)$ & $2.24 \times 10^{-4}(-15 \%)$ \\
$Q_{2}$ & $94.1(+704 \%)$ & $634.8(+92 \%)$ & $1640.4(+41 \%)$ & $10 \times 10^{-4}(+79 \%)$ & $5.03 \times 10^{-4}(+91 \%)$ \\
$Q_{0.5}$ & $4.33(-63 \%)$ & $147.1(-55 \%)$ & $927.7(-20 \%)$ & $3.28 \times 10^{-4}(-41 \%)$ & $1.59 \times 10^{-4}(-40 \%)$ \\
\hline Wind runs & & & & \\
$W_{\text {Jan }}$ & $0(-100 \%)$ & $13.9(-96 \%)$ & $256.8(-78 \%)$ & $4.06 \times 10^{-4}(-27 \%)$ & $1.90 \times 10^{-4}(-28 \%)$ \\
$W_{\text {Aug }}$ & $25.4(+117 \%)$ & $412.8(+25 \%)$ & $1435.3(+23 \%)$ & $6.25 \times 10^{-4}(+12 \%)$ & $3.02 \times 10^{-4}(+15 \%)$ \\
$W_{0.9}$ & $49.0(+319 \%)$ & $478.0(+45 \%)$ & $1296.8(+12 \%)$ & $6.29 \times 10^{-4}(+13 \%)$ & $2.80 \times 10^{-4}(+6 \%)$ \\
$W_{1.1}$ & $0(-100 \%)$ & $118.9(-64 \%)$ & $894.4(-23 \%)$ & $4.89 \times 10^{-4}(-12 \%)$ & $2.45 \times 10^{-4}(-7 \%)$ \\
$W_{180^{\circ}}$ & $13.8(+18 \%)$ & $235.5(-29 \%)$ & $909.4(-22 \%)$ & $4.97 \times 10^{-4}(-11 \%)$ & $2.45 \times 10^{-4}(-7 \%)$ \\
$W_{-90^{\circ}}$ & $14.6(+25 \%)$ & $296(-10 \%)$ & $1020.5(-12 \%)$ & $5.07 \times 10^{-4}(-9 \%)$ & $2.51 \times 10^{-4}(-5 \%)$ \\
$W_{+} 90^{\circ}$ & $20.3(+74 \%)$ & $390.9(+18 \%)$ & $1240(+7 \%)$ & $6.68 \times 10^{-4}(+20 \%)$ & $2.85 \times 10^{-4}(+8 \%)$ \\
\hline
\end{tabular}


(a)

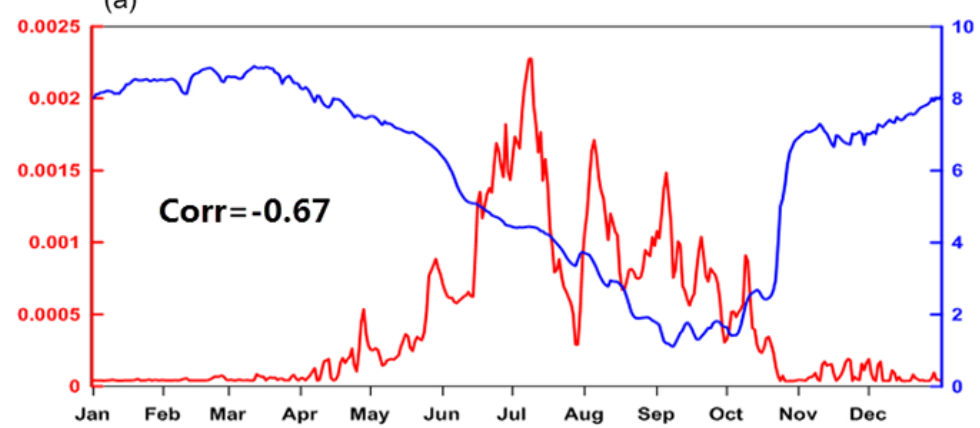

(b)

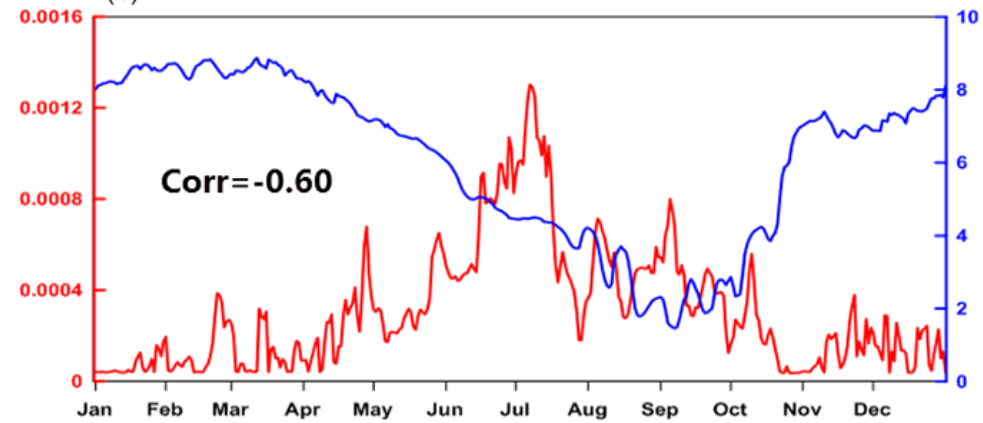

(c)

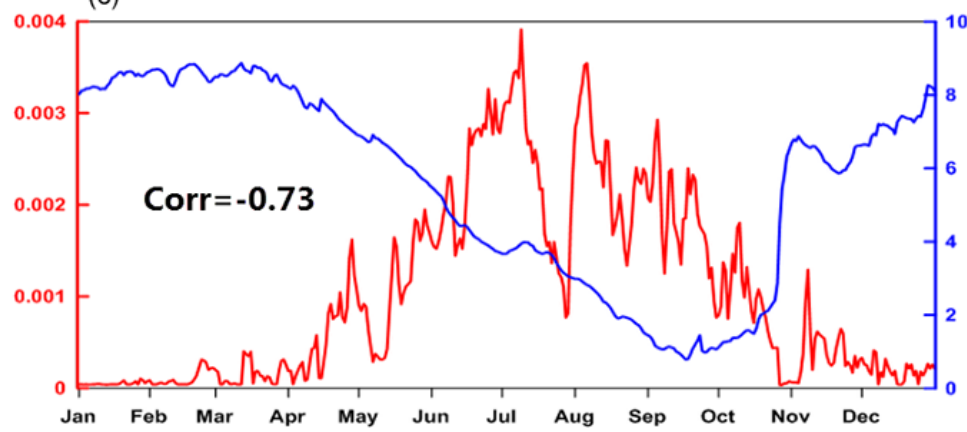

(d)

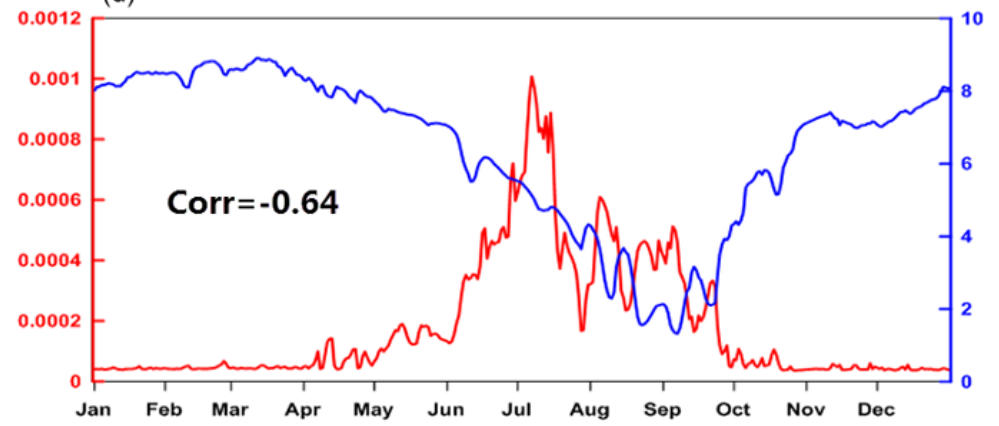

Figure 9. The correlation between the bottom dissolved oxygen concentration and $N^{2}$ at the station of $123^{\circ} \mathrm{E}, 31^{\circ} \mathrm{N}$. The blue curve represents the bottom dissolved oxygen concentration, and the red curve represents $N^{2}$. (a-d) The base run, $Q_{\text {const }}, Q_{2}$, and $Q_{0.5}$, respectively.

area off Yangtze Estuary was the minimum and reduced by nearly $30 \%$ compared with base model run. The integrated hypoxic area was greatest when the summer wind came from the west $\left(W_{+90^{\circ}}\right)$, increasing by nearly $20 \%$. The summer wind direction from the east $\left(W_{-90^{\circ}}\right)$ led to a reduction by nearly $10 \%$ of the integrated hypoxic area (Table 2 ).

\section{Discussion}

\subsection{Model validation}

In Fig. 5, the difference of nitrate concentration between the model results and in situ data was relatively obvious. The 
(a)

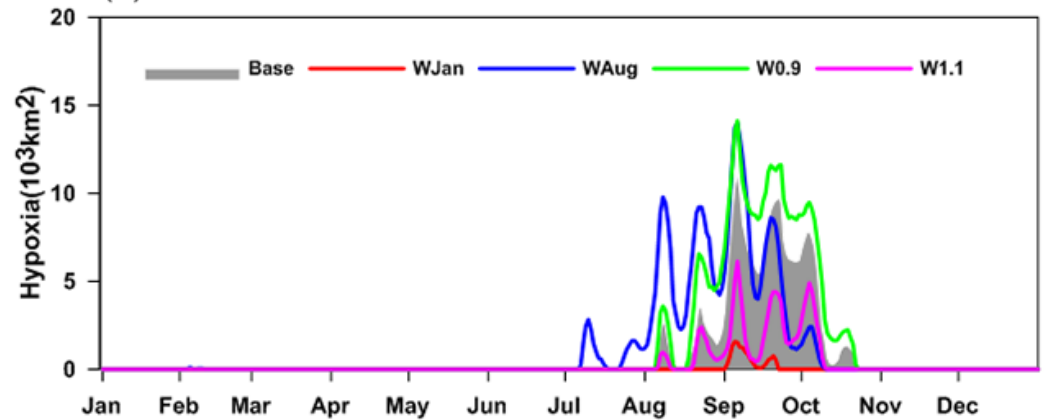

(b)

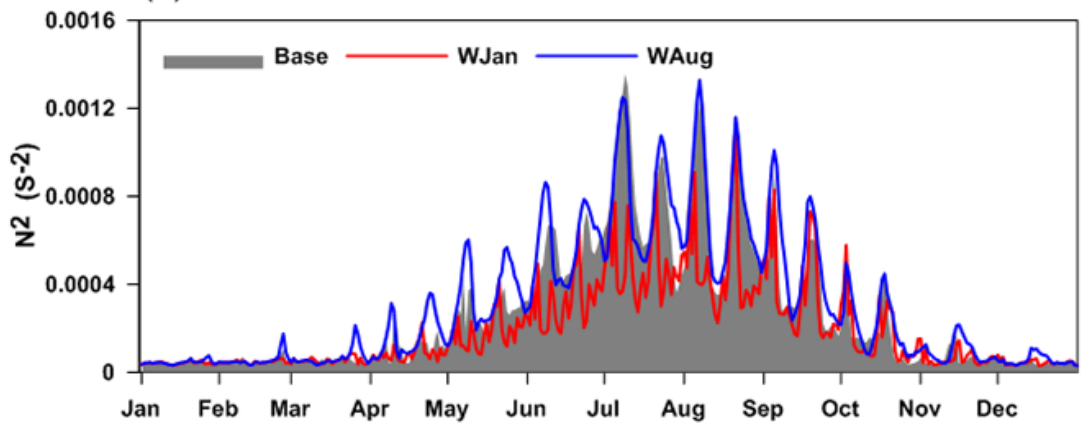

(c)

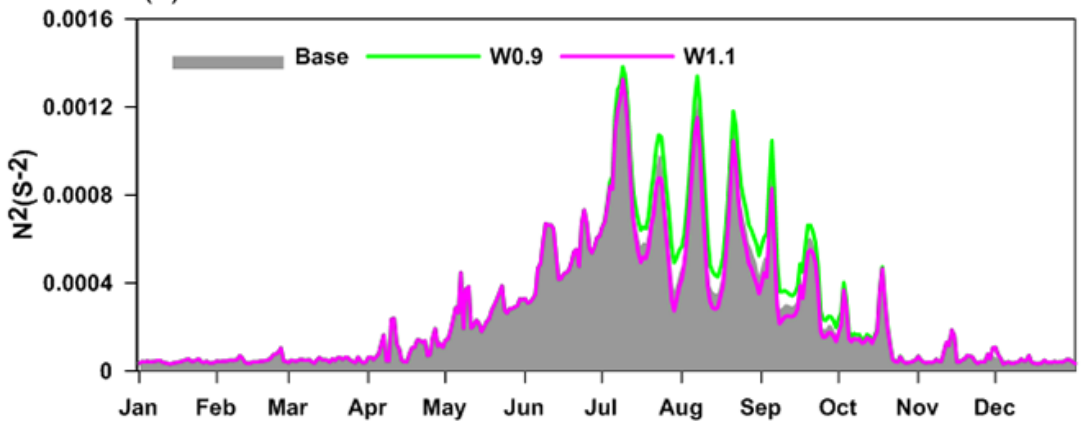

Figure 10. (a) The comparison of the simulated hypoxic area $\left(\mathrm{DO}<2 \mathrm{mg} \mathrm{L}^{-1}\right)$ on the wind variation runs. (b, c) Averaged stratification $N^{2}$ for the base run (gray shadow) and wind variation runs.

Table 3. Monthly and annually mean river discharge $\left(\mathrm{m}^{3} \mathrm{~s}^{-1}\right)$ in 2010 .

\begin{tabular}{lrrrrrrrrrrrr}
\hline Month & Jan & Feb & Mar & Apr & May & Jun & Jul & Aug & Sep & Oct & Nov & Dec \\
\hline $\begin{array}{l}\text { River } \\
\text { discharge }\end{array}$ & 13038 & 15847 & 21116 & 31105 & 39852 & 51022 & 61872 & 51785 & 42498 & 31037 & 18599 & 15419 \\
\hline $\begin{array}{l}\text { Annual mean } \\
\text { discharge }\end{array}$ & & & & & & 32766 & & & & & & \\
\hline
\end{tabular}

reason for this may be that the river input of nitrate was the monthly average in the model. As shown in Fig. 7, hypoxia was present mainly in the southern and northern parts along the coast of the study area. The model results of the hypoxic area were similar to that observed by Liu (2012). Model validation results showed that the model can reproduce the variations of biological variables and the hypoxia in summer at the bottom of the Yangtze Estuary to a certain extent. There were some deviations from the observed results in some areas, which could be due to the complex biogeochemical cycle, parameterization, physical field, and so on. It is suggested that the model can capture some basic conditions of the key physical and biological processes in the Yangtze Estuary, such as the distribution of SST, SSS, chlorophyll, 
(a)
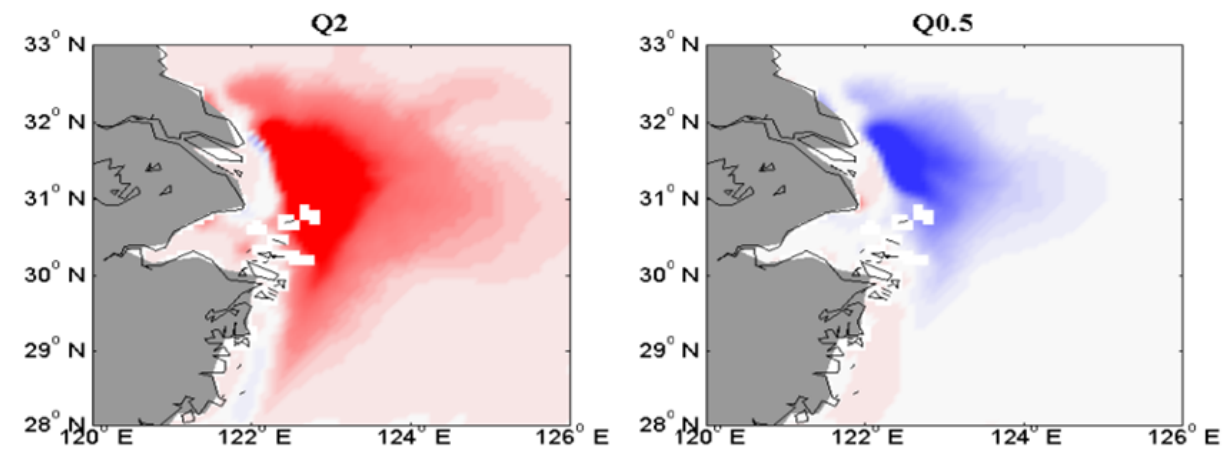

(b)
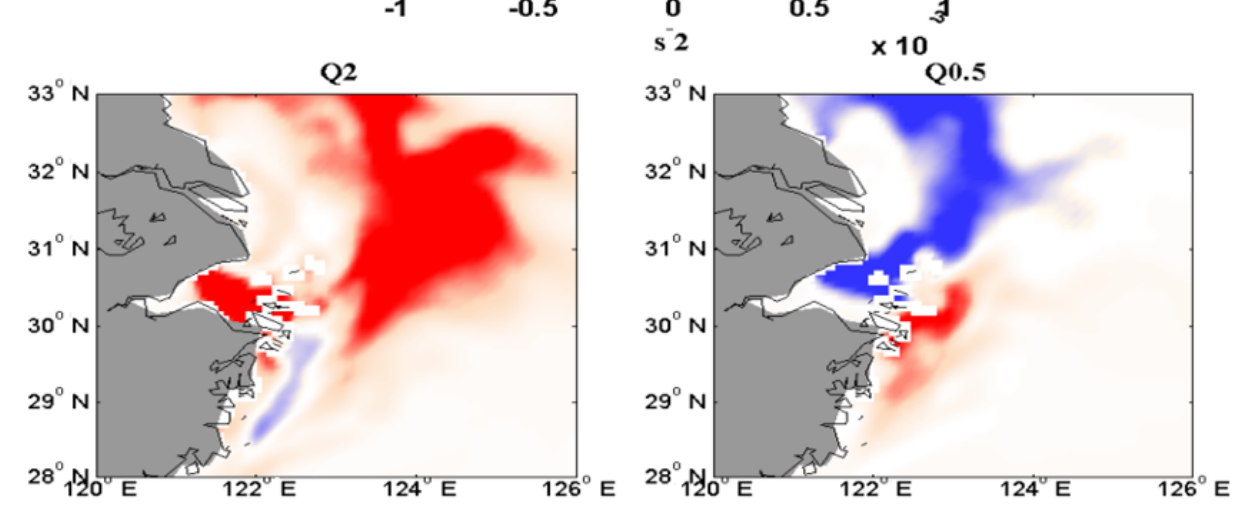

(c)
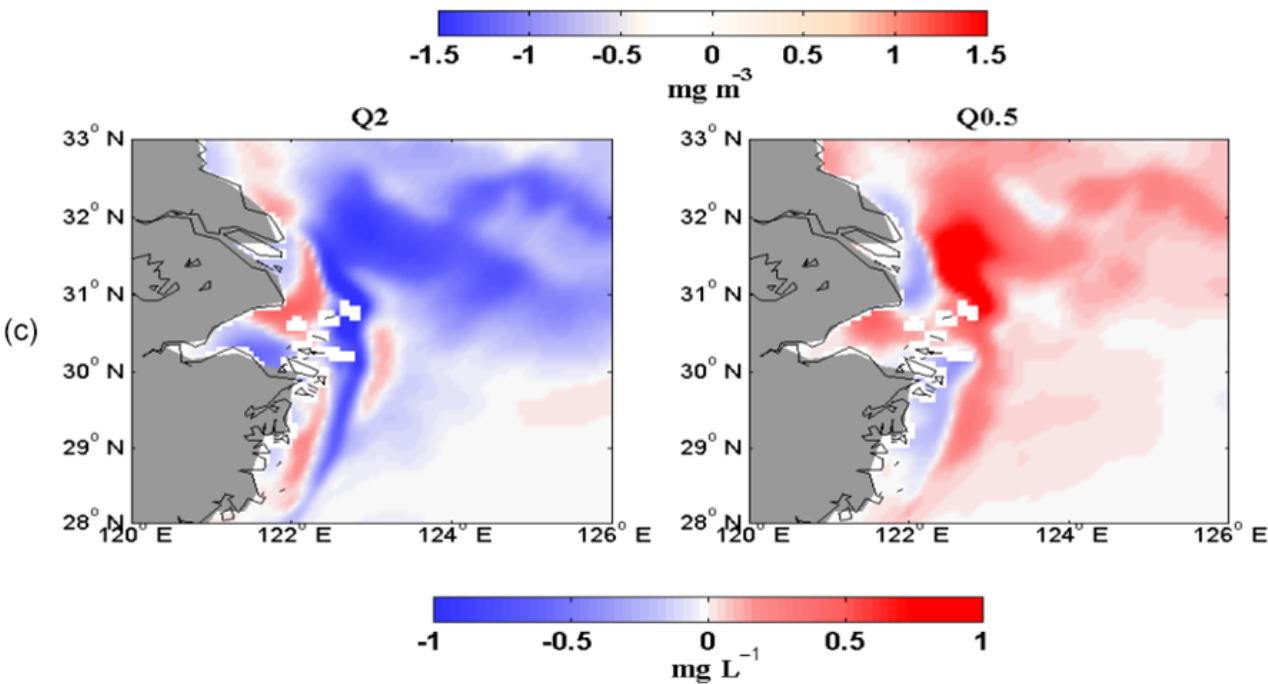

Figure 11. (a) The deviation in summer (7-9 months) stratification $\left(N^{2}\right)$ of $Q_{2}$ and $Q_{0.5}$ from the base run. (b) The deviation in summer (7-9 months) chlorophyll concentration of $Q_{2}$ and $Q_{0.5}$ from the base run. (c) The deviation in summer (7-9 months) bottom dissolved oxygen concentration of $Q_{2}$ and $Q_{0.5}$ from the base run.

nutrients, and circulation pattern. This will be helpful for further exploring the mechanism of the formation of hypoxia off the Yangtze Estuary.

\subsection{River discharge}

Stratification was an important indicator of oxygen concentration in bottom water, preventing the exchange of DO from the surface to bottom and eventually resulting in hypoxia in the bottom water (Rabouille et al., 2008). The simulated seasonal cycle of hypoxic area on the $Q_{\text {const }}$ run was similar to 
(a)

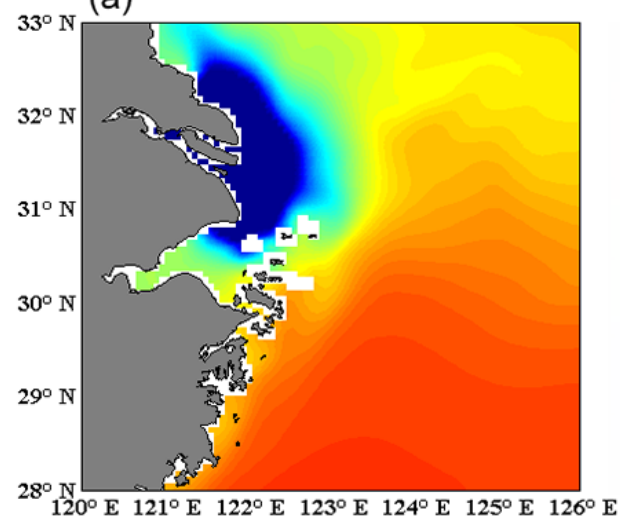

(b)

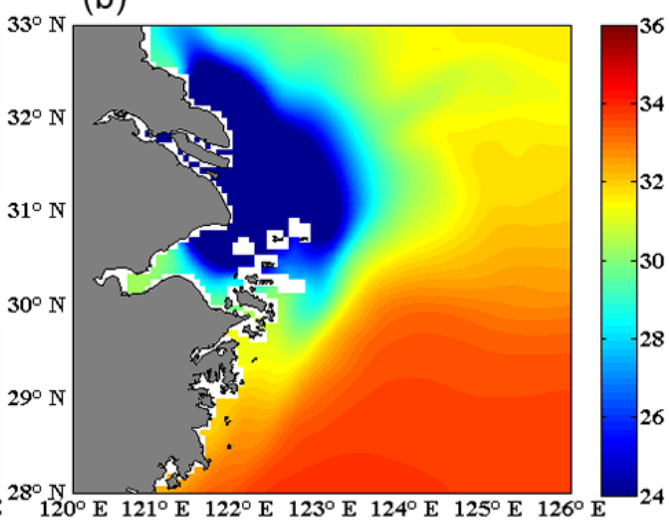

(c)

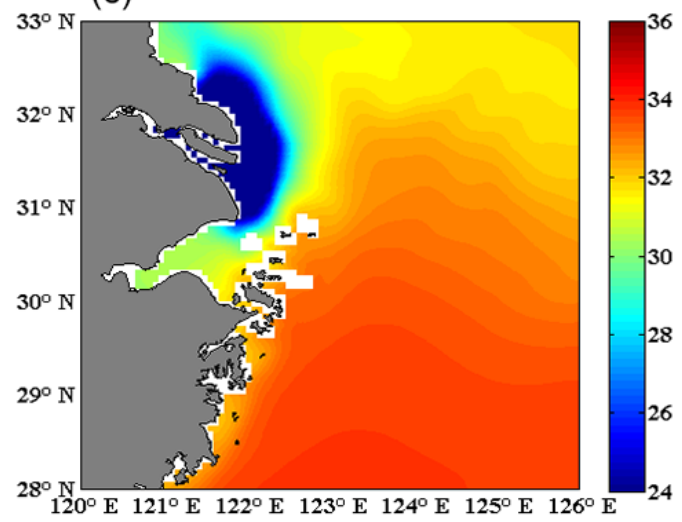

Figure 12. Averaged surface salinity for the period July to September in 2010 for the river runs. (a-c) The base run, $Q_{2}$, and $Q_{0.5}$, respectively.

the base model run (Fig. 8a), which suggested that the temporal variation in river discharge was not an important factor controlling the seasonal cycle of hypoxic area. However, the magnitude of Yangtze River discharge variation could lead to significant changes on the hypoxic area. Increasing river discharge led to an expansion of the lighter, fresher river plume water offshore and an enhancement of stratification (Fig. 11a), which limited the effective supplement of high surface DO. This result consequently caused a reduction of bottom DO (Fig. 11c). Additionally, the integrated hypoxic area increased by $92 \%$, the lowest value of bottom DO from the base model run was $1.11 \mathrm{mg} \mathrm{L}^{-1}$, while in the $Q_{\text {const }}$ run it reduced to $0.78 \mathrm{mg} \mathrm{L}^{-1}$. Decreasing river discharge reduced the stratification (Fig. 11a) and thereby significantly increased the vertical oxygen flux through the pycnocline. As a result, the integrated hypoxic area decreased by $55 \%$ and the lowest value of bottom DO increased to $1.32 \mathrm{mg} \mathrm{L}^{-1}$. These results were consistent with the results of previous work conducted by Scully (2013). In addition, there was a significant negative correlation between the bottom DO and the stratification (Fig. 9). When the water stratification was strong, the bottom DO was low, while when the water stratification was weak, the bottom DO was high. Fig- ure 11a further shows that doubling or halving the river discharge respectively enhanced or reduced stratification over the majority of the shelf in summer months, resulting in a decrease or increase of the bottom DO.

Increasing river discharge led to offshore extension of the fresher river plume water (Fig. 12b), bringing rich nutrients eastward. As a result, surface chlorophyll over the majority of the eastern shelf increased in the $Q_{2}$ run relative to the base model run (Fig. 11b), which caused the continuous decrease in oxygen levels at the lower layer through decomposition of organic matters. In contrast, decreasing the river discharge confined the river plume water to near the river mouths (Fig. 12c), which limited the nutrients eastward. As seen in Fig. 11b, surface chlorophyll decreased over the majority of the shelf in the $Q_{0.5}$ run compared to the base model run. Thus, bottom DO increased and hypoxic zone decreased due to the decomposition of organic matters being reduced in the bottom water.

\subsection{Wind forcing}

Strong wind could trigger strong vertical mixing and promote the vertical exchange of DO, which broke the formation of 

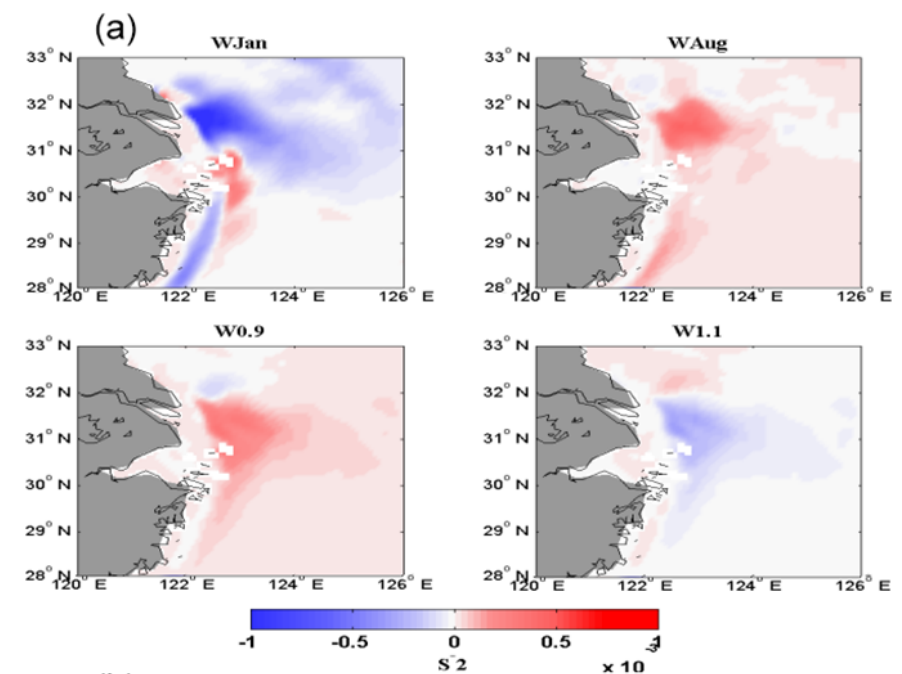

(b)
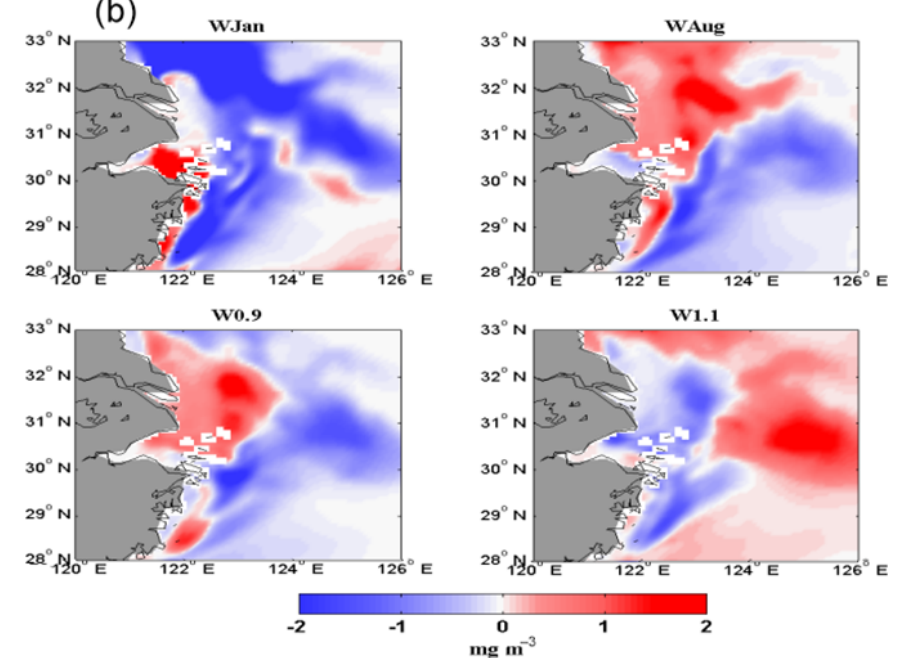

(c)
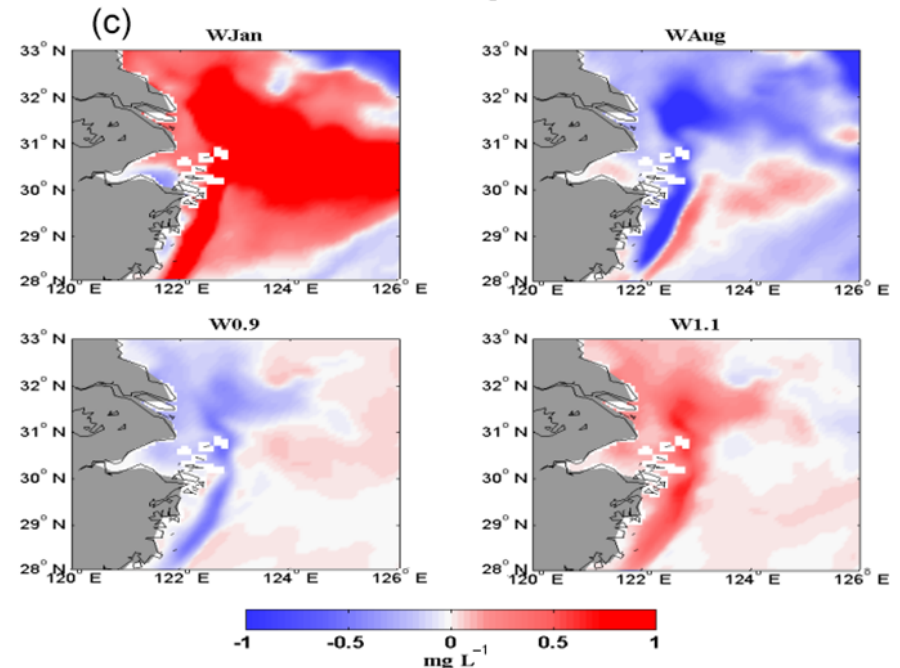

Figure 13. (a) The deviation in summer (7-9 months) stratification $\left(N^{2}\right)$ of wind variation runs from the base model. (b) The deviation in summer (7-9 months) chlorophyll concentration of wind variation runs from the base model. (c) The deviation in summer (7-9 months) bottom dissolved oxygen concentration of wind variation runs from the base model. 

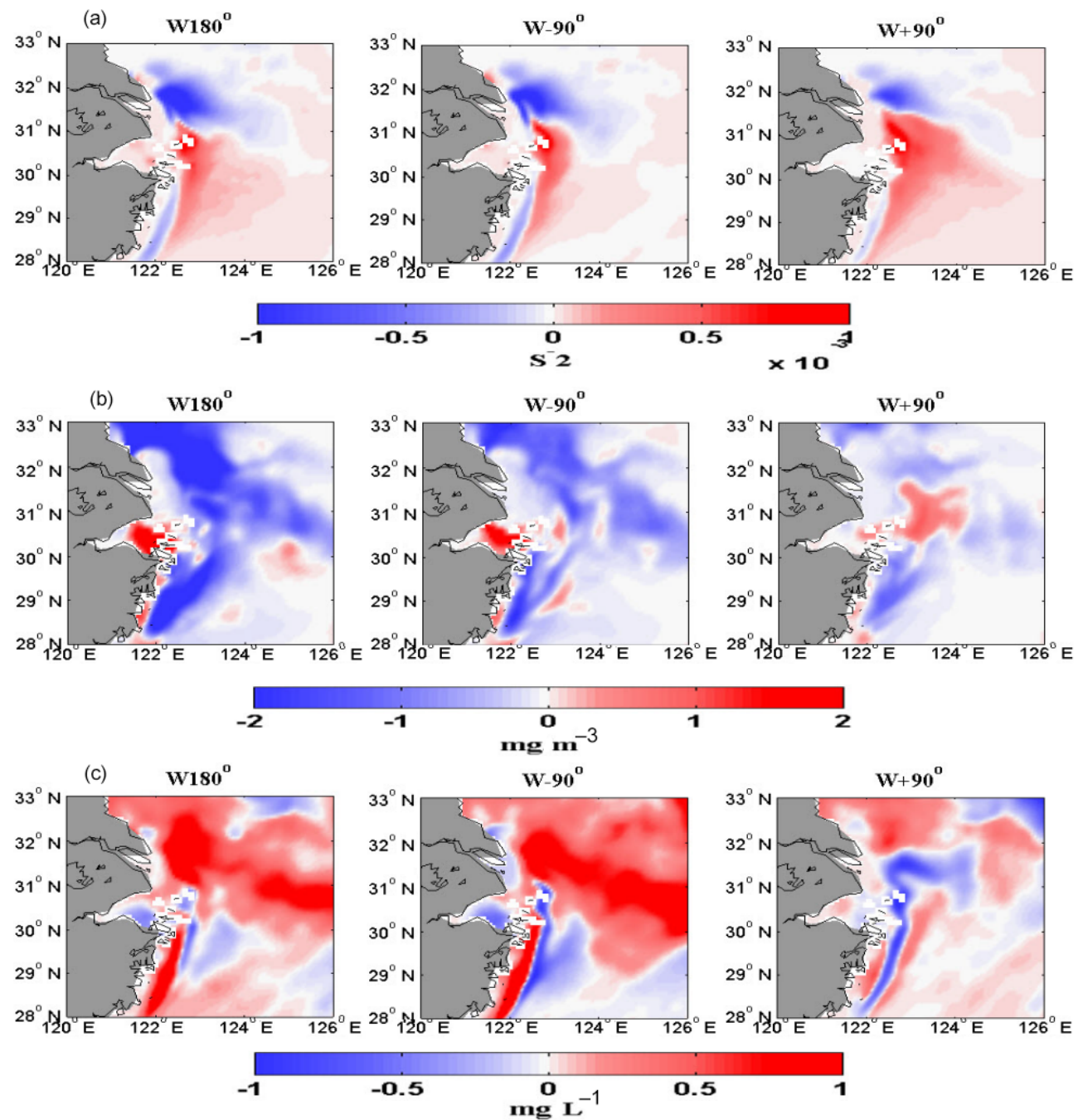

Figure 14. (a) The deviation in summer (7-9 months) stratification $\left(N^{2}\right)$ of wind direction variation runs from the base model. (b) The deviation in summer (7-9 months) chlorophyll concentration of wind direction variation runs from the base model. (c) The deviation in summer (7-9 months) bottom dissolved oxygen concentration of wind direction variation runs from the base model.

hypoxia (Chen et al., 2014; Ni et al., 2014). Our simulated results showed that the variation in wind speed and direction significantly influences the stratification and hence the hypoxic area. In the $W_{\mathrm{Jan}}$ wind run, the strong wind homogenized the water column, reducing stratification and producing essentially no hypoxia throughout the year. Figure 13a shows that $N^{2}$ was negative in the most areas, except in the eastern part of the Hangzhou Bay, which suggested that the water mixing was strong and the vertical flux of DO increased in the $W_{\text {Jan }}$ wind run. As a result, the bottom DO concentration increased (Fig. 13c), and there was almost no hypoxia in the bottom water off the Yangtze Estuary in the $W_{\mathrm{Jan}}$ wind run. In addition, the strong northwestern wind in January resulted in strong estuarine residual velocities that brought the high DO from the northern Yellow Sea to Yangtze River Estuary. Therefore, even though the average stratification strength in the $W_{\text {Jan }}$ wind run was stronger than the $Q_{0.5}$ run (Table 2),
$W_{\text {Jan }}$ did not develop any hypoxia throughout the year. From Fig. 13b it can be seen that the surface chlorophyll concentration of the $W_{\mathrm{Jan}}$ wind run was significantly lower than the base model run. The possible reason for this was that the strong wind from the northwest in the $W_{\text {Jan }}$ wind run drove downwelling due to Ekman dynamics, which decreased the concentration of surface chlorophyll and ultimately led to an enhancement of DO through lower decomposition of organic matters. These finds were the same as the results reported in the study conducted in the northern Gulf of Mexico shelf by Feng (2014). Above all, in the $W_{\mathrm{Jan}}$ wind run there was almost no hypoxia adjacent to the Yangtze River Estuary in the summer.

In contrast, in the $W_{\text {Aug }}$ wind run, the persistently weak wind enhanced the stratification and reduced the vertical flux of DO, resulting in a decrease of bottom DO and promotion of widespread hypoxia. In addition, the concentration of sur- 

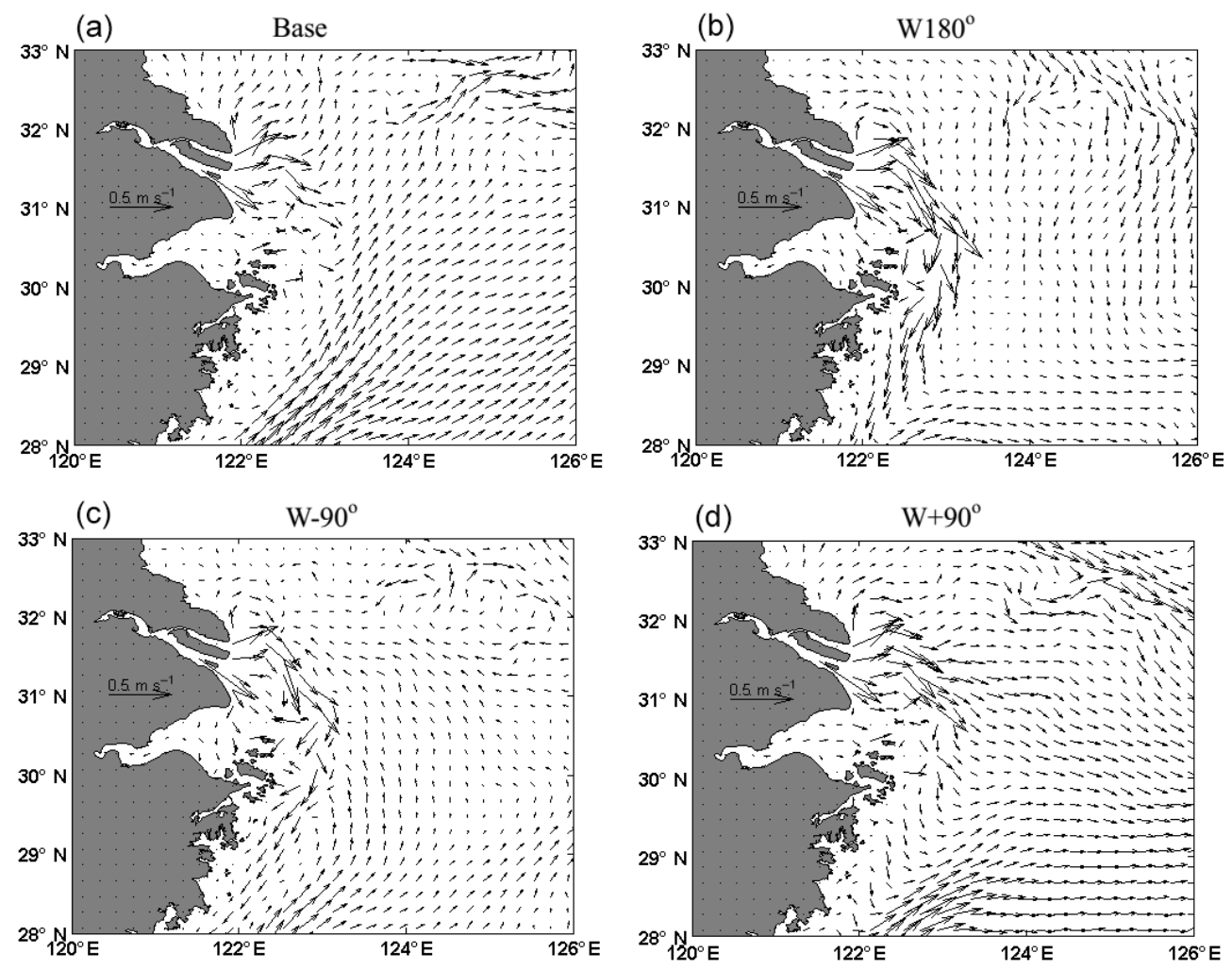

Figure 15. Circulation pattern in the surface water: (a) base model run; (b) $W_{180^{\circ}} ;$ (c) $W_{-} 90^{\circ} ;(\mathbf{d}) W_{+90^{\circ}}$.

face chlorophyll increased adjacent to Yangtze Estuary and along the coast of Zhejiang in the $W_{\text {Aug }}$ wind run (Fig. 13b). This result suggested that bottom DO declined with the decomposition of organic matters.

Simulations of hypoxic area showed significant variability in the response to wind speed. In the $W_{1.1}$ wind run, the increase in wind speeds was thought to play a key role in breaking down stratification and increasing the vertical flux of DO. Increased wind speeds generally raised bottom DO concentration (Fig. 13c). This finding was similar to the results conducted on the Louisiana coast, where the authors suggested that wind-induced vertical mixing could result in significant reductions in the hypoxic area (Wiseman et al., 1997). As shown in Fig. $13 \mathrm{~b}$, in the area of $28-32^{\circ} \mathrm{N}, 122-123.5^{\circ} \mathrm{E}$, decreased surface chlorophyll resulted in lower DO consumption, which increased the DO in the bottom water. In contrast, in the $W_{0.9}$ wind run, the DO flux from the upper layers due to stronger stratification was reduced. Additionally, increased surface chlorophyll concentration in the area to the north of $30^{\circ}$ led to huge DO consumption caused by the decay of dead phytoplankton (Fig. 13b). These results worked together to decrease the bottom DO and create hypoxic expansion (Fig. 13c). Scully (2013) illustrated how changes in wind are associated with stratification and thereby hypoxia on the shelf. The author found that increased wind speed decreased the hypoxic area, whereas decreased wind speed fa- cilitated hypoxia development. These findings are consistent with our results.

Changes in wind direction also significantly influence the hypoxic area off Yangtze Estuary. As seen in Fig. 14a, when the mean summer wind direction was from the north $\left(W_{180^{\circ}}\right)$, stratification decreased north of $31^{\circ} \mathrm{N}$ and along the coast of Zhejiang relative to the base model run. This led to an enhancement of vertical DO flux. In contrast, near to the Hangzhou Bay, the vertical DO flux was reduced, associated with increased water stratification, resulting in decreased bottom DO (Fig. 14c). Under the control of the northerly wind $\left(W_{180^{\circ}}\right)$, Zhejiang coastal current was enhanced (Fig. 15b). Thus the high DO from the northern Yellow Sea was transported to the Yangtze Estuary. This further led to increased bottom DO off Yangtze Estuary. From Fig. 14b it can be seen that surface chlorophyll concentration at $W_{180^{\circ}}$ was lower than the base model run. We attributed this to the fact that wind from the north drives downwelling due to Ekman dynamics. Decreased DO consumption was caused by the reduced decay of dead phytoplankton. When the summer wind was from the east $\left(W_{-90^{\circ}}\right)$, the average water stratification was similar to the $W_{180^{\circ}}$ wind run, but the integrated hypoxic area in the $W_{-90^{\circ}}$ wind run was larger than the $W_{180^{\circ}}$ run. This may be related to the horizontal distribution of chlorophyll concentration. As shown in Fig. 14b, surface chlorophyll concentration was higher in the $W_{-90^{\circ}}$ wind run than 
the $W_{180^{\circ}}$ run, which would lead to more DO consumption caused by organic matter decomposition at $W_{-90^{\circ}}$. The circulation distribution (Fig. 15c) shows that the westward flow $\left(31-32^{\circ} \mathrm{N}, 122-126^{\circ} \mathrm{E}\right)$ transported the high DO to the west, which increased the DO in the bottom water in this area.

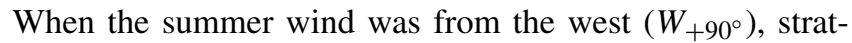
ification was the strongest in the three wind direction runs. Integrated hypoxic area also reached the maximum. There are three reasons for this. Firstly, Fig. 14a shows that stratification was stronger in most areas, except north of the $31.5^{\circ} \mathrm{N}$ relative to the base model run, which suggested that in most areas the water mixing was weak and the vertical flux of DO reduced. Secondly, under the influence of the westerly wind, the low DO could spread from the trough off the Yangtze Estuary to the east due to eastward flow (Fig. 15d). Thirdly, in Fig. 14b an area of relatively high chlorophyll concentration off Yangtze Estuary in the $W_{+} 90^{\circ}$ wind run is seen. The reason for this may be that the rich nutrients from Yangtze River expand to the eastward under control of the westerly wind. As a result, it promotes the growth of phytoplankton. The decomposition of dead phytoplankton was another important factor for the decreased bottom DO. These reasons work together to create hypoxic conditions.

\section{Conclusions}

In this study, a three-dimensional coupled physicalbiological model was used to analyze the hypoxia off the Yangtze Estuary. This study highlighted that river discharge, wind speed, and wind direction all had significant impacts on the hypoxia. The seasonal cycle of hypoxia was relatively insensitive to the temporal variability in river discharge. However, the integrated hypoxic area was very sensitive to the magnitude of river discharge. Increases in the magnitude of river discharge led to enhanced stratification, promotion of the growth of phytoplankton associated with higher nutrients, and thereby an increase of the hypoxic area off the Yangtze Estuary. In contrast, decreases in the magnitude of river discharge reduced the stratification and surface chlorophyll concentration and hence significantly decreased the hypoxic area.

Model simulations demonstrated that wind speed and wind direction play an important role in the integrated hypoxic area. When the winds in January were repeated all year, the hypoxic zone nearly disappeared as the result of the strong water mixing induced by strong northerly winds. Persistently weak winds in August enhanced stratification and facilitated hypoxia development. Increasing wind speed weakened stratification and chlorophyll concentration and hence decreased the hypoxic area, while decreasing wind speed did the opposite. Wind direction significantly influenced the extent of hypoxia. Among the direction runs, the integrated hypoxic area was greatest when the summer wind came from the west $\left(W_{+90^{\circ}}\right)$, which was enhanced by nearly
$20 \%$. When the summer wind direction was from the north $\left(W_{180^{\circ}}\right)$, the integrated hypoxic area off Yangtze Estuary was at a minimum. The integrated hypoxic area reduced by nearly $10 \%$ when the wind was from the east $\left(W_{-90^{\circ}}\right)$.

The model did not include inorganic phosphorus and therefore assumed that primary production was limited by light and nitrogen only. In future studies, the model needs to consider the dynamics of inorganic phosphorus. In addition, increasing the number of monitoring cruises per year and setting up additional long-term moorings in the East China Sea would be useful to further validate biogeochemical variables and environmental factors.

Acknowledgements. We would like to thank the anonymous reviewers and the editor, Ivan Federico, for their valuable contributions that allowed us to improve the manuscript substantially. This study is supported by the National Natural Science Foundation of China under contract no. 41222038, 41076011 and 41206023, and the National Basic Research Program of China (g973h Program) under contract no. 2011CB403606, and the Strategic Priority Research Program of the Chinese Academy of Sciences Grant no. XDA1102010403, and the National Key Research and Development Program of China, no. 2016YFC1401605.

Edited by: I. Federico

Reviewed by: two anonymous referees

\section{References}

Carnes, M. R.: Description and Evaluation of GDEM-V 3.0. Naval Research Laboratory, NRL/MR/7330—09-9165, Stennis Space Center, 2009.

Chapman, D. C.: Numerical treatment of cross-shelf open boundaries in a barotropic coastal ocean model, J. Phys. Oceanogr., 15, 1060-1075, 1985.

Chen, J., Ni, X., Liu, M., Chen, J., Mao, Z., Jin, H., and Pan, D.: Monitoring the occurrence of seasonal low-oxygen events off the Changjiang Estuary through integration of remote sensing, buoy observations, and modeling, J. Geophys. Res.-Ocean., 119, 5311-5322, 2014.

Diaz, R. J.: Overview of hypoxia around the world, J. Environ. Qual., 30, 275-281, 2001.

Feng, Y., Fennel, K., Jackson, G. A., DiMarco, S. F., and Hetland, R. D.: A model study of the response of hypoxia to upwellingfavorable wind on the northern Gulf of Mexico shelf, J. Mar. Syst., 131, 63-73, 2014.

Fennel, K., Wilkin, J., Levin, J., and Moisan, J.: Nitrogen cycling in the Middle Atlantic Bight: Results from a three-dimensional model and implications for the North Atlantic nitrogen budget, Global Biogeochem. Cy., 20, GB3007, doi:10.1029/2005GB002456, 2006.

Fennel, K., Hu, J., Laurent, A., Marta-Almeida, M., and Hetland, R.: Sensitivity of hypoxia predictions for the northern Gulf of Mexico to sediment oxygen consumption and model nesting, J. Geophys. Res.-Ocean., 118, 990-1002, 2013.

Flather, R.: A tidal model of the northwest European continental shelf, Mem. Soc. Roy. Sci. Liege, 10, 141-164, 1976. 
Goni, M., Gordon, E., Monacci, N., Clinton, R., Gisewhite, R., Allison, M., and Kineke, G.: The effect of Hurricane Lili on the distribution of organic matter along the inner Louisiana shelf (Gulf of Mexico, USA), Cont. Shelf Res., 26, 2260-2280, 2006.

$\mathrm{Gu}, \mathrm{H}$.: The maximum value of dissolved oxygen in its vertical distribution in Yellow SEA, Acta Oceanol. Sin., 2, 70-79, 1980.

Haidvogel, D. B., Arango, H., Budgell, W. P., Cornuelle, B. D., Curchitser, E., Di Lorenzo, E., Fennel, K., Geyer, W. R., Hermann, A. J., and Lanerolle, L.: Ocean forecasting in terrain-following coordinates: Formulation and skill assessment of the Regional Ocean Modeling System, J. Comput. Phys., 227, 3595-3624, 2008.

Karlson, K., Rosenberg, R., Bonsdorff, E., Gibson, R., Barnes, M., and Atkinson, R.: Temporal and spatial large-scale effects of eutrophication and oxygen deficiency on benthic fauna in Scandinavian and Baltic waters - A review, Oceanogr. Mar. Biol., 40, 427-489, 2002.

Lewis, M. R., Cullen, J. J., and Platt, T.: Phytoplankton and thermal structure in the upper ocean: consequences of nonuniformity in chlorophyll profile, J. Geophys. Res.-Ocean, 88, 2565-2570, 1983.

Li, H., Chen, J., Lu, Y., Jin, H., Wang, K., and Zhang, H.: Seasonal variation of DO and formation mechanism of bottom water hypoxia of Changjiang River Estuary, J. Mar. Sci., 29, 78-87, 2011.

Liu, K.-K., Chao, S. Y., Shaw, P. T., Gong, G. C., Chen, C. C., and Tang, T. Y.: Monsoon-forced chlorophyll distribution and primary production in the South China Sea: Observations and a numerical study, Deep-Sea Res. Pt. I, 49, 1387-1412, 2002.

Liu, K.-K., Chao, S.-Y., Lee, H.-J., Gong, G.-C., and Teng, Y.-C.: Seasonal variation of primary productivity in the East China Sea: A numerical study based on coupled physical-biogeochemical model, Deep-Sea Res. Pt. II, 57, 1762-1782, 2010.

Liu, X., Shen, H., and Huang, Q.: Concentration variation and flux estimation of dissolved inorganic nutrient from the Changjiang River, Chin. J. Oceanol. Limn., 33, 332-340, 2002.

Liu, Z., Xu. R., Liu, C., Qin, Y., and Cai, P.: Characters of hypoxia area off the Yangtze River EStuary and its influence, Mar. Sci. Bull., 31, 588-593, 2012.

Lü, X., Qiao, F., Xia, C., Zhu, J., and Yuan, Y.: Upwelling off Yangtze River estuary in summer, J. Geophys. Res.-Ocean., 111, C11020, doi:10.1029/2005JC003250, 2006

Marchesiello, P., McWilliams, J. C., and Shchepetkin, A.: Open boundary conditions for long-term integration of regional oceanic models, Ocean Modell., 3, 1-20, 2001.

Mellor, G. and Yamada, Y.: Development of a turbulence closure model for geophysical fluid problems, Geophys, 20, 851-875, 1982.

Morel, A. and Berthon, J. F.: Surface pigments, algal biomass profiles, and potential production of the euphotic layer: Relationships reinvestigated in view of remote-sensing applications, Limnol. Oceanogr., 34, 1545-1562, 1989.

Murphy, R. R., Kemp, W. M., and Ball, W. P.: Long-Term Trends in Chesapeake Bay Seasonal Hypoxia, Stratification, and Nutrient Loading, Estuar. Coast., 34, 1293-1309, 2011.

Ni, X., Huang, D., Zeng, D., Zhang, T., Li, H., and Chen, J.: The impact of wind mixing on the variation of bottom dissolved oxygen off the Changjiang Estuary during summer, J. Mar. Sys., 154, 122-130, 2014.
Ning, X., Lin, C., Su, J., Liu, C., Hao, Q., and Le, F.: Longterm changes of dissolved oxygen, hypoxia, and the responses of the ecosystems in the East China Sea from 1975 to 1995, J. Oceanogr., 67, 59-75, 2011.

Obenour, D. R., Michalak, A., and Scavia, D.: Assessing biophysical controls on Gulf of Mexico hypoxia through probabilistic modeling, Ecol. Appl., 25, 492-505, 2015.

Rabouille, C., Conley, D. J., Dai, M. H., Cai, W. J., Chen, C. T. A., Lansard, B., Green, R., Yin, K., Harrison, P. J., Dagg, M., and McKee, B.: Comparison of hypoxia among four river-dominated ocean margins: The Changjiang (Yangtze), Mississippi, Pearl, and Rhône rivers, Cont. Shelf Res., 28, 1527-1537, 2008.

Scully, M. E.: Wind Modulation of Dissolved Oxygen in Chesapeake Bay, Estuaries and Coasts, J. ERF, 33, 1164-1175, 2010a.

Scully, M. E.: The Importance of Climate Variability to WindDriven Modulation of Hypoxia in Chesapeake Bay, J. Phys. Oceanogr., 40, 1435-1440, 2010 b.

Scully, M. E.: Physical controls on hypoxia in Chesapeake Bay: A numerical modeling study, J. Geophys. Res.-Ocean., 118, 12391256, 2013.

Shchepetkin, A. F. and McWilliams, J. C.: The regional oceanic modeling system(ROMS): a split - explicit, free - surface, topography-following-coordinate oceanic model, Ocean Modell., 9, 347-404, 2005.

Vaquer-Sunyer, R. and Duarte, C.: Thresholds of hypoxia for marine biodiversity, P. Natl. Acad. Sci. USA, 105, 15452-15457, 2008.

Wang, B.: Hydromorphological mechanisms leading to hypoxia off the Changjiang estuary, Mar. Environ. Res., 67, 53-58, 2009.

Wei, H., He, Y., Li, Q., Liu, Z., and Wang, H.: Summer hypoxia adjacent to the Changjiang Estuary, J. Mar. Syst., 67, 292-303, 2007.

Wei, Q., Wang, B., Chen, J., Xia, C., Qu, D., and Xie, L.: Recognition on the forming-vanishing process and underlying mechanisms of the hypoxia off the Yangtze River estuary, Sci. China Earth Sci., 58, 628-648, 2015.

Wilson, R. E., Swanson, R. L., and Crowley, H. A.: Perspectives on long-term variations in hypoxic conditions in western Long Island Sound, J. Geophys. Res., 113, C12011, doi:10.1029/2007jc004693, 2008.

Wiseman, W. J., Rabalais, N. N., Turner, R. E., Dinnel, S. P., and Macnaughton, A.: Seasonal and interannual variability within the Louisiana coastal current: stratification and hypoxia, J. Mar. Syst., 12, 237-248, 1997.

Li, X., Yu, Z., Song, X., and Cao, X.: The seasonal characteristics of dissolved oxygen distribution and hypoxia in the Changjiang Estuary, J. Coast. Res., 27, 52-62, 2011.

Xia, M. and Jiang, L.: Influence of wind and river discharge on the hypoxia in a shallow bay, Ocean Dynam., 65, 665-678, 2015.

Yin, K., Lin, Z., and Ke, Z.: Temporal and spatial distribution of dissolved oxygen in the Pearl River Estuary and adjacent coastal waters, Cont. Shelf Res., 24, 1935-1948, 2004.

Zhou, F., Huang. D., Ni, X., Xuan, J., Zhang, J., and Zhu, K.: Hydrographic analysis on the multi-time scale variability on hypoxia adjacent to the Changjiang River estuary, Acta Ecol. Sin., 30, 4728-4720, 2010

Zhu, Z.-Y., Zhang, J., Wu, Y., Zhang, Y.-Y., Lin, J., and Liu, S.-M.: Hypoxia off the Changjiang (Yangtze River) Estuary: Oxygen depletion and organic matter decomposition, Mar. Chem., 125, 108-116, 2011. 